\title{
Internal waves in the Strait of Gibraltar and their role in the vertical mixing processes within the Bay of Algeciras
}

\author{
J. Chioua $^{\mathrm{a}}$, M. Bruno ${ }^{\mathrm{b}, *}$, A. Vázquez ${ }^{\mathrm{c}, \mathrm{b}}$, M. Reyes ${ }^{\mathrm{b}}$, J.J. Gomiz ${ }^{\mathrm{c}, \mathrm{b}}$, R. Mañanes $^{\mathrm{c}, \mathrm{b}}$, O. Álvarez ${ }^{\mathrm{c}}$, \\ C. González ${ }^{c}$, L. López ${ }^{\mathrm{d}}, \mathrm{J}$. Gómez-Enri ${ }^{\mathrm{c}}$ \\ ${ }^{a}$ Institut National de Recherche Halieutique, Centre Régional de Tanger, 5268, Dradeb, 90000 Tanger, Morocco \\ ${ }^{\mathrm{b}}$ Centro Andaluz de Ciencia y Tecnología Marinas (CACYTMAR), Universidad de Cádiz, Campus de Puerto Real S/N, Puerto Real, 11510 Cádiz, Spain \\ ${ }^{\mathrm{C}}$ Departamento de Física Aplicada, Universidad de Cádiz, Avda República Saharaui S/N, Puerto Real, 11510 Cádiz, Spain \\ ${ }^{\mathrm{d}}$ National Institute of Water and Atmospheric Research (NIWA), Lauder, Omakau, Private Bag 50061, Central Otago 9352, New Zealand
}

\section{A R T I C L E I N F O}

\section{Article history:}

Received 22 February 2013

Accepted 14 April 2013

Available online 24 April 2013

\section{Keywords:}

internal waves

tidal current

Strait of Gibraltar

vertical mixing

Algeciras Bay

\begin{abstract}
A B S T R A C T
This article presents some of the results of an oceanographic survey carried out in the Bay of Algeciras (Strait of Gibraltar) as part of a research project intended to assess the environmental quality of the Bay. One of the most interesting findings was the step-like patterns presented by density profiles within the Bay, which were indicative of notable vertical mixing activity there. The analysis of the observations indicates that those mixing processes may be explained by the interaction between the local internal tide dynamics and the large amplitude internal waves entering the Bay, which seem to originate from the Camarinal Sill region.
\end{abstract}

(c) 2013 Elsevier Ltd. All rights reserved.

\section{Introduction}

The Bay of Algeciras is a semi-enclosed water body at the southern tip of the Iberian Peninsula that opens to the south into the easternmost side of the Strait of Gibraltar (see map in Fig. 1). It is around $10 \mathrm{~km}$ long by $8 \mathrm{~km}$ wide, with a maximum depth of about $400 \mathrm{~m}$ in the centre of the Bay.

Although the Bay has suffered considerable anthropogenic pollution for many decades, in the literature there are very few studies dealing with the circulation and renewal of water masses within the Bay. The first reference to the physical oceanography of the Bay of Algeciras is that appearing in an old study by Odon de Buen (1924), where colder surface water was reported in the Bay, compared with the adjacent surface water flowing through the Strait of Gibraltar.

Although not many studies have been carried out specifically within the Bay of Algeciras, several researchers have studied the nearby oceanographic areas, the Strait of Gibraltar and Sea of Alboran. One of the phenomena analyzed most frequently is the high amplitude internal waves generated over the Camarinal Sill.

\footnotetext{
* Corresponding author.

E-mail addresses: miguel.bruno@uca.es, mbrunomejias@hotmail.com (M. Bruno).
}

On this topic, Watson and Robinson $(1990,1991)$ have reported the eastward orientation displayed by internal wave fronts near the mouth of the Bay, due to the refraction effects induced by the crossstrait interface slope and the cross-strait shear of the upper layer current, and the subsequent penetration of the refracted internal wave trains into the Bay. More recently, Álvarez et al. (2011) have reproduced, using a 3D numerical model, the penetration into the Bay of the internal waves generated at the Camarinal Sill; the same authors have also indicated the importance of the diffraction processes affecting the propagation of the internal wave trains when they approach the mouth of the Bay.

In this oceanographic area the largest internal waves are formed by the interaction of the barotropic tidal flow with the bottom topography of the Camarinal Sill and the stratified water column. The initial depression of the internal waves arises by non-linear processes and non-hydrostatic dispersion, and considerable amplitudes are reached, often up to 100 m, (Armi and Farmer, 1988; Richez, 1994; Vázquez et al. 2006).

This article presents an analysis of the role of large amplitude internal waves generated at the main sill of the Strait of Gibraltar (the Camarinal Sill) in explaining, along with the local tidal forcing, the vertical mixing processes within the Bay of Algeciras. After describing the observations of tidal and shorter period dynamics, an analysis of the mixing processes across the Atlantic- 


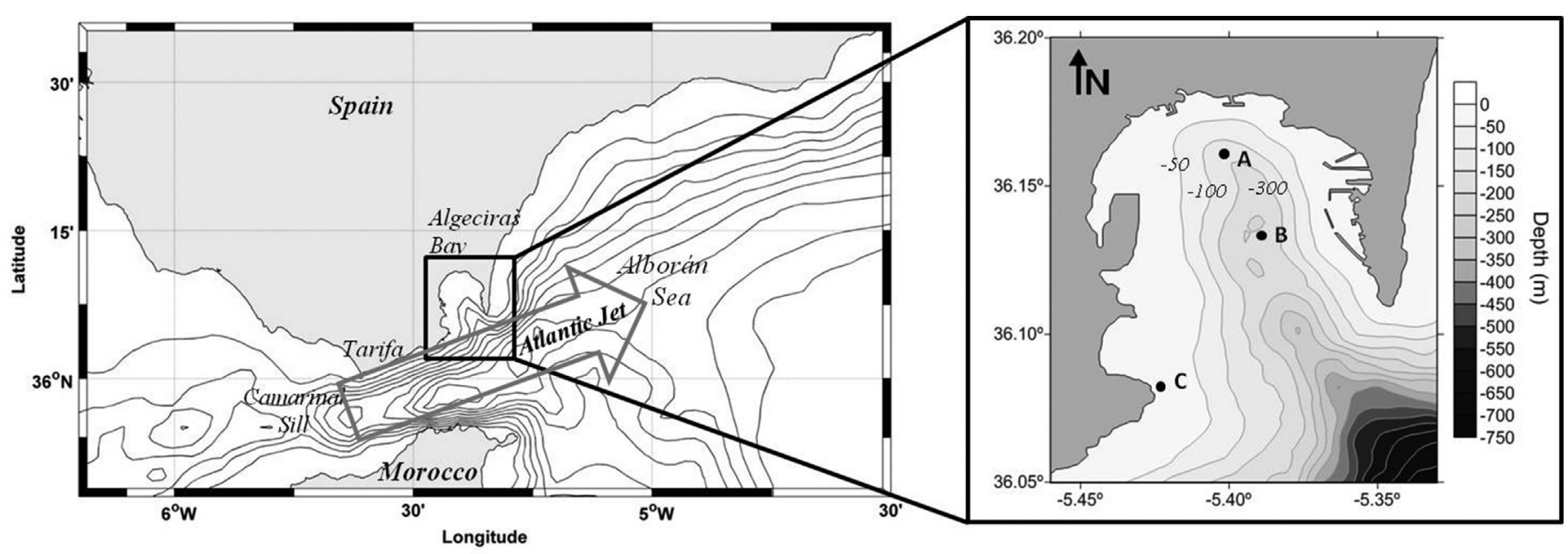

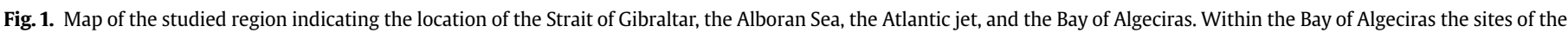

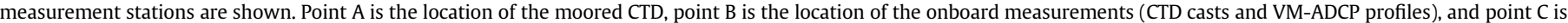
the location of the bottom pressure sensor, moored at $21 \mathrm{~m}$ depth.

Mediterranean Interface (AMI) within the Bay is presented. Finally, the results are discussed and the main conclusions are drawn.

\section{Observations of tidal and shorter period dynamics within the Bay of Algeciras}

The data used in this study were obtained in NovemberDecember 2006 during an oceanographic cruise carried out aboard the R/V “Mytilus". Two different types of records are analyzed: first, a time series, three weeks long, of salinity, temperature and pressure recorded at a sampling interval of $1 \mathrm{~min}$, in two autonomous CTDs moored at station A ( $220 \mathrm{~m}$ depth); and second, CTD (Conductivity, Temperature and Depth) and $300 \mathrm{KHz}$ VM ADCP (Vessel Mounted Acoustic Doppler Current Profiler) profiles obtained onboard during a semidiurnal cycle at station B $(\sim 340 \mathrm{~m}$ depth) (see Fig. 1). VM ADCP data were sampled at 1 min intervals and vertical resolution for VM ADCP and CTD profiles was 4 and $1 \mathrm{~m}$ respectively. CTD and VM ADCP data were obtained during two different semidiurnal cycles, one at neap tide and another at spring tide, which will be referred to in the text as stage 1 and 2 respectively.

As complementary information, an ASAR image of sea surface roughness from the ENVISAT satellite and two aerial photographs (one taken from the International Space Station and another from an aircraft during a commercial flight) will be used. A bottom pressure sensor has also been used to record the surface tide during the measurement period at Punta Carnero (point $C$ on map of Fig. 1).

\subsection{Basic tidal dynamics}

The evolution of the time series at the mooring places, and profiles of density and velocity taken from the vessel, are shown in Figs. 2 and 3. Current profiles have been averaged over the period of time that the vessel remained on station in order to eliminate shorter-than-tidal-period oscillation in the current; the averaging times are shown in Table 1. CTD profiles were obtained during the down-cast of the probe, which lasted roughly $5 \mathrm{~min}$.

The information regarding the stage 1 (neap tide) in Fig. 2 is analyzed first. At low tide (casts $C_{4}$ and $C_{5}$ ), the direction of the tidal current is towards the head of the Bay in the upper layer, and towards the mouth in the lower layer. In the time between casts $\mathrm{C}_{4}$ and $C_{5}$, the depth of the pycnocline has increased. This behaviour indicates that, during this time interval, tidal current transport in the upper layer is greater than that in the lower layer. In the middle of the flood tide (cast $\mathrm{C}_{1}$ ) the tidal current has weakened in the upper layer, and the pycnocline has reached its deepest position. At high tide (cast $C_{2}$ ) we found, as expected, the reverse situation to that found at low tide: the direction of the tidal current is towards the mouth in the upper, and towards the head in the lower layer. Finally, in the middle of the ebb tide (cast $C_{3}$ ), the tidal current has weakened again in the whole water column. In summary, tidal current intensities reach their maximum at low and high tide, while minimum intensities occur in the middle of the flood and ebb tide. Note that tidal current intensities hardly exceed $0.2 \mathrm{~m} \mathrm{~s}^{-1}$.

The time series and vertical profiles corresponding to the stage 2 (spring tide) are shown in Fig. 3. At low tide (cast $\mathrm{C}_{1}$ ) the direction of the tidal current is towards the head of the Bay in the upper, and towards the mouth in the lower layer; and the pycnocline is located at a relatively shallow depth (about $40 \mathrm{~m}$ ). From low tide to high tide (casts $C_{2}$ and $C_{3}$ ), the maximum tidal current intensity is reached in the upper layer, and this coincides with a steep plunge of the pycnocline, to a depth below $100 \mathrm{~m}$. Surprisingly, only $2 \mathrm{~h}$ after high tide, in the middle of the ebb tide (cast $C_{4}$ ), a rapid intensification occurs in the tidal current towards the mouth in the upper, and towards the head in the lower layer. About $3 \mathrm{~h}$ later, at the start of the low tide (cast $C_{5}$ ), currents have weakened and show the lowest values within the tidal cycle. These rapid changes in the current velocity intensity and direction could indicate the presence of internal overtides (i.e. an $\mathrm{M}_{4}$ signal) which are more prone to develop during spring tide conditions. Note that, as expected, tidal current intensity reaches values up to $0.35 \mathrm{~m} \mathrm{~s}^{-1}$, greater than those found in neap tide.

A remarkable feature in the density profiles is the sharp increase in density of the upper layer that takes place during the spring tide (stage 2). This change seems to be related to the behaviour of the Atlantic jet entering the Alboran Sea. This jet is the main hydrodynamic feature of the upper layer in the easternmost part of the Strait. It has a typical width of about $30 \mathrm{~km}$ (Viúdez et al., 1998) and an eastward velocity of around $1 \mathrm{~m} \mathrm{~s}^{-1}$. It is the main carrier of the Atlantic inflow water into the Alboran Sea. As shown in Figs. 4 and 5 days before the start of stage 1 (on November 9th 2006) the Atlantic jet occupied the whole transversal dimension of the Strait on its easternmost side. Four days later, on November 13th, the jet started to veer to the south, and moved away from the Spanish coast, leaving the Bay of Algeciras in direct contact with the waters of the 


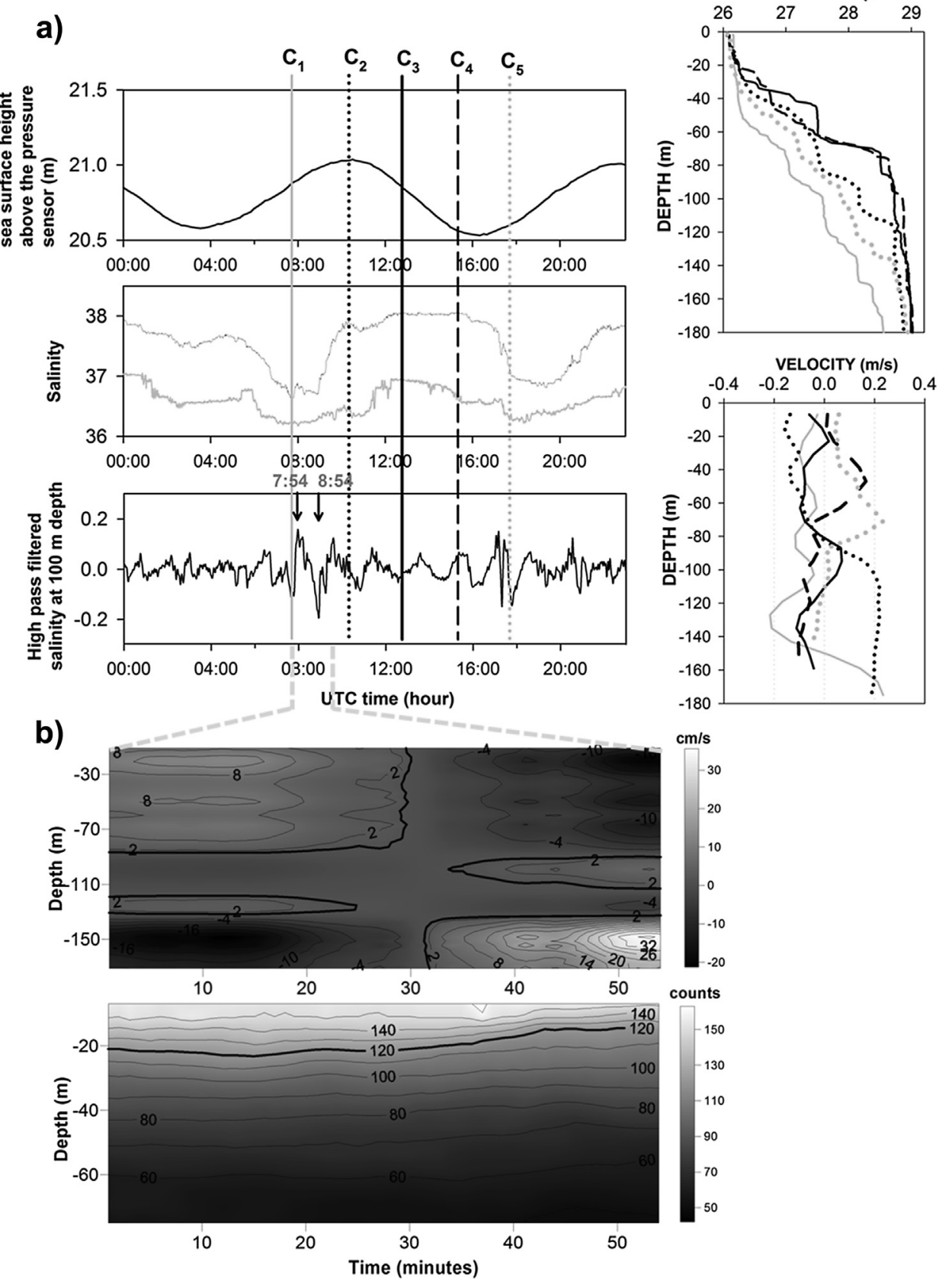

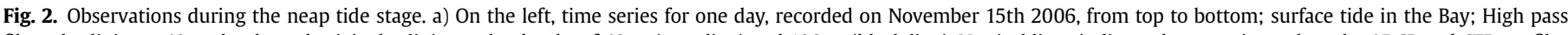

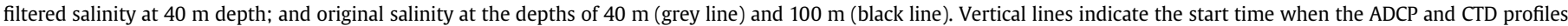

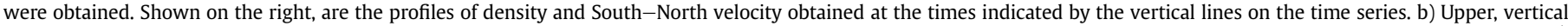

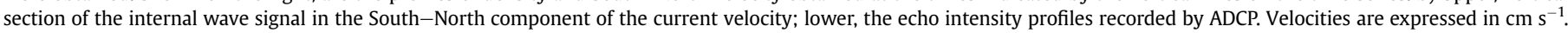

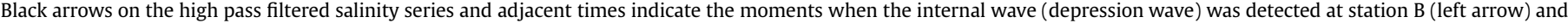
at station $\mathrm{A}$ (right arrow).

western Alboran gyre. This situation persisted until the end of stage 2 , as can be observed in the satellite images of December 4 th. Under this behaviour of the Atlantic Jet the upper layer waters of the Bay become saltier and colder, resembling the coastal waters of the northwestern Alboran Sea. Fig. 5 shows the progressive change in the upper layer waters recorded at station A during the whole measurement period. The corresponding density change due to this water exchange could have changed the phase speed of the internal tide within the Bay, which in turn produced the different behaviour shown by the internal tide between the two stages.

\subsection{Shorter-than-tidal period oscillations}

To isolate the salinity signal with oscillation periods shorter than the tidal ones, the original time series of salinity were filtered using a FFT filter. Looking at the resulting high pass filtered salinity series shown in Figs. 2 and 3, we can see short-period oscillations with periods ranging from 20 to $120 \mathrm{~min}$, which arrive in packets separated by time intervals of about $12 \mathrm{~h}$. These signals are indicative of shorter-than-tidal period internal wave activity within the Bay. 
$\operatorname{DENSITY}\left(\sigma_{t}\right)$
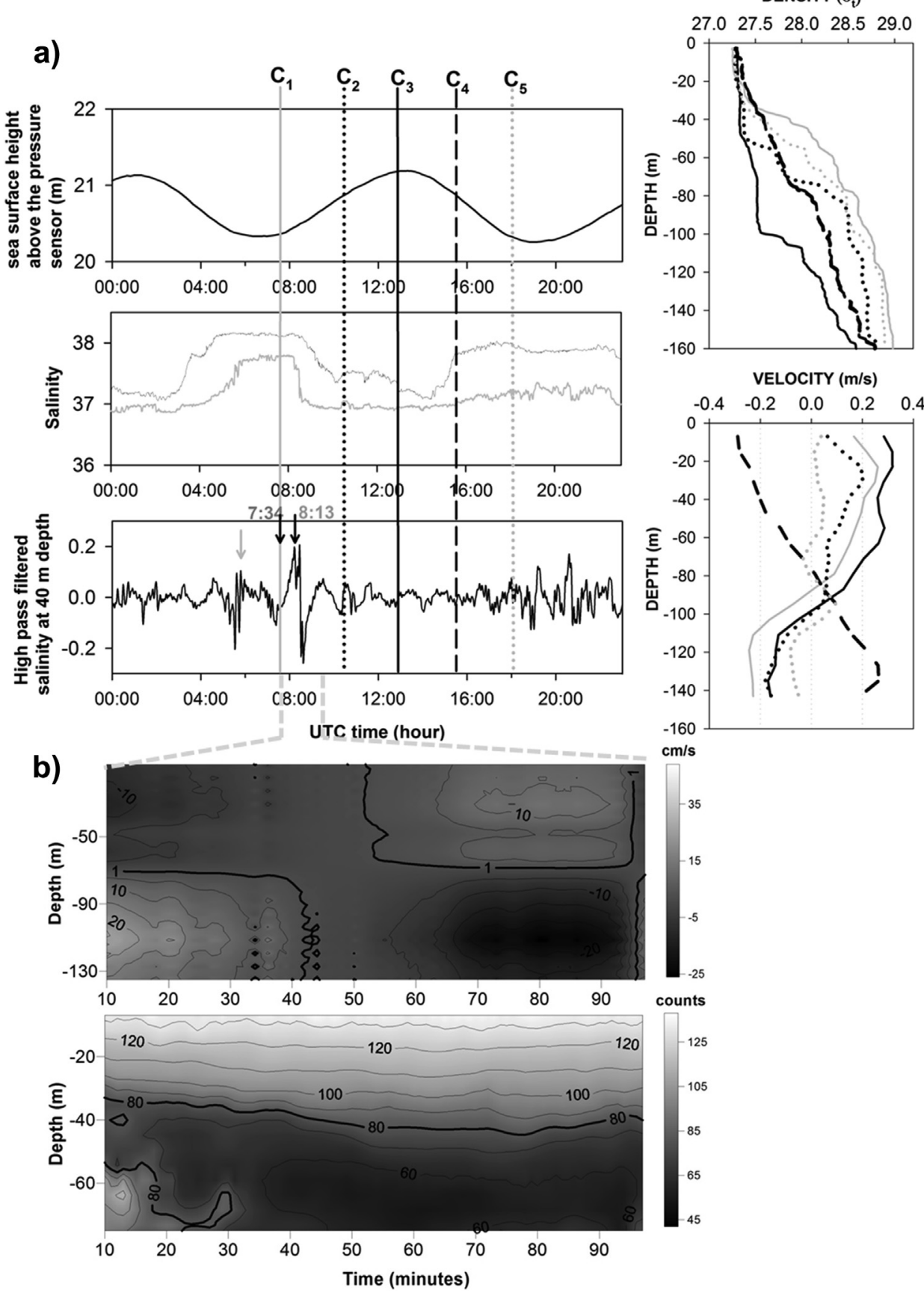

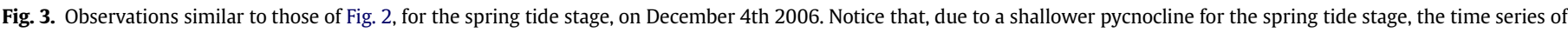

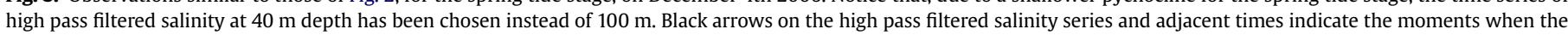
internal wave (elevation wave) was detected at station B (left arrow) and at station A (right arrow).

In order to isolate the signal of these internal waves in the current velocity we have designed the following specific procedure:

1. First of all, in order to remove as much as possible of the time variability associated with periods longer than those expected for the internal waves (10-60 min), we have subtracted the mean value of the recorded values at each bin depth from the original records. It is expected that, after the subtraction, the resulting time series no longer includes the tidal variability recorded during the sampling period, which is assumed to be small. Hereinafter, this signal will be called the 'short period signal'.

2. In a second step, the baroclinic variability contained in the short period signal is isolated; this is done by applying to it an empirical orthogonal function (EOF) decomposition (Kundu et al., 1975). The EOF has been described as a useful technique for separating the barotropic and baroclinic variability of currents (i.e. tidal currents) (Candela et al., 1990; Bruno et al., 2000, 2006). Once these common patterns are determined, the signal of the analyzed series can be expressed as: 
Table 1

Times of starting and finishing the CTD casts performed at station B. The time of finishing ADCP measurements at the stations is indicated in parenthesis.

\begin{tabular}{|c|c|c|c|c|c|c|}
\hline \multirow[t]{2}{*}{ Cast } & \multicolumn{3}{|l|}{ Stage 1} & \multicolumn{3}{|l|}{ Stage 2} \\
\hline & Date & $\begin{array}{l}\text { Start } \\
\text { (UTC) }\end{array}$ & Finish (UTC) & Date & $\begin{array}{l}\text { Start } \\
\text { (UTC) }\end{array}$ & Finish (UTC) \\
\hline $\mathrm{C}_{1}$ & $15 / 11 / 2006$ & $07: 42$ & $7: 48(8: 47)$ & $04 / 12 / 2006$ & $7: 34$ & $7: 40(8: 54)$ \\
\hline $\mathrm{C}_{2}$ & $15 / 11 / 2006$ & $10: 14$ & $10: 20(11: 28)$ & $04 / 12 / 2006$ & $10: 15$ & $10: 21(11: 10)$ \\
\hline $\mathrm{C}_{3}$ & $15 / 11 / 2006$ & $12: 50$ & $12: 56(13: 53)$ & $04 / 12 / 2006$ & $12: 39$ & $12: 45(13: 48)$ \\
\hline $\mathrm{C}_{4}$ & $15 / 11 / 2006$ & $15: 15$ & $15: 21(16: 12)$ & $04 / 12 / 2006$ & $15: 16$ & $15: 22(16: 25)$ \\
\hline $\mathrm{C}_{5}$ & $15 / 11 / 2006$ & $17: 38$ & $17: 44(18: 35)$ & $04 / 12 / 2006$ & $17: 52$ & $17: 58(18: 53)$ \\
\hline
\end{tabular}

$u(z, t)=\sum_{j=1}^{M} e_{j}(z) a_{j}(t)$

where $u(z, t)$ is the current velocity component in the predominant direction (the South-North component in our case), $z$ denotes the spatial position (i.e. vertical coordinate), $t$ is time, $e_{j}(z)$ are the EOFs (also known as spatial coefficients), $a_{j}(t)$ are the temporal amplitudes of the EOFs, and $M$ is the number of EOFs (equal to the number of time series included in the analysis).

The records chosen for the analysis were those obtained during the first casts (casts denoted by $C_{1}$ ) in each of the two measurement stages (see Figs. 2 and 3 ). As can be seen, these casts were performed during a time interval within which the passage of the short period internal waves was expected (see vertical black arrows in Figs. 2 and 3 ); these are the waves, travelling northward, that were detected in the CTD mooring at station A several minutes later.

The results from the EOF analysis are shown in Fig. 6. In the two stages the first EOF mode, the one explaining the major percentage of variance of the analyzed series, was a baroclinic mode with values that change their sign at about the depth of the pycnocline.

In Figs. $2 b$ and $3 b$, we can see the time evolution of the current velocity profiles corresponding to the first EOF. In stage 1 , the captured baroclinic signal seems to be consistent with a northward-propagating depression wave, with induced currents directed northward in the upper and southward in the lower layer; this is followed by an elevation wave, with induced currents directed southward in the upper and northward in the lower layer. In stage 2, the corresponding baroclinic signal is an elevation wave followed by a depression. Note that the time evolution of the echo intensity profiles measured by the ADCP at the same time as the current profiles (Figs. $2 \mathrm{~b}$ and $3 \mathrm{~b}$ ) support the previous description of the observed baroclinic disturbances. Low values of echo intensity, which depends on the concentration of suspended particles, are shallower/deeper depending on whether the pycnocline is shallower/deeper.

The inferred arrival times of these perturbations at station A (see black arrows in Figs. 2a and 3a) are in good agreement with the theoretical travel times of the internal waves between the stations, which can be computed using the first order long-wave non-linear theory. Under this theory, the phase speed of a first-mode internal solitary wave may be computed (Lee and Beardsley, 1974) as:

$c=c_{0}+\alpha a$

where $a$ is the amplitude of the solitary wave; and $c_{0}$ is the linear phase speed of the first baroclinic mode, which is equal to the highest eigenvalue of the Sturm-Liouville problem (Lee and Beardsley, 1974; Vlasenko et al., 2005).

$\frac{c_{0}^{2}}{N^{2}(z)} \bar{\psi}_{z z}(z)=\bar{\psi}(z)$ where $\bar{\psi}(z)$ is the amplitude of the stream function corresponding to the 2D problem disregarding Earth rotation effects, with coordinates $x$ and $z$ oriented, respectively, in the propagation direction of the internal wave and upward; and $N(z)$ is the Brunt-Väisala profile characterizing the background density field. Subscripts indicate derivatives with respect to the $z$ co-ordinate. The coefficient $\alpha$ in Equation (2) is given by

$\alpha=\frac{1}{6} \frac{\int_{0}^{H} \bar{\rho}_{z z} \bar{\psi}_{1}^{3}(z) \mathrm{d} z}{\int_{0}^{H} \bar{\rho}_{z} \bar{\psi}_{1}^{2}(z) \mathrm{d} z}$

where $\bar{\rho}(z)$ is the undisturbed density profile; $H$ is the bottom depth; and $\bar{\psi}_{1}(z)$ is the eigen function of the problem given by the Equation (3) corresponding to the first baroclinic mode. Note that in the framework of this long wave theory, internal waves propagate only horizontally, and group and phase speed differ only by a very small value (Watson, 1994).

Using the $N(z)$ profiles computed from the density profiles obtained at station $B$ corresponding to the casts $C_{1}$ and $C_{2}$ in both survey stages, for an amplitude of the solitary wave $a=15 \mathrm{~m}$ inferred from the echo intensity profiles (Figs. 2b and $3 \mathrm{~b}$ ), we get the values $c=1.06 \mathrm{~m} \mathrm{~s}^{-1}\left(\mathrm{C}_{1}\right)$ and $c=1.12 \mathrm{~m} \mathrm{~s}^{-1}\left(\mathrm{C}_{2}\right)$ for stage 1 , and $c=1.03 \mathrm{~m} \mathrm{~s}^{-1}\left(C_{1}\right)$ and $c=0.98 \mathrm{~m} \mathrm{~s}^{-1}\left(C_{2}\right)$ for stage 2 . With these values of $c$, the travel times of the internal perturbations from station $\mathrm{B}$ to $\mathrm{A}$, taking the distance between these stations as $3.24 \mathrm{Km}$, are $0.85 \mathrm{~h}\left(\mathrm{C}_{1}\right)$ and $0.80 \mathrm{~h}\left(\mathrm{C}_{2}\right) \mathrm{h}$ for stage 1 and $0.87 \mathrm{~h}\left(\mathrm{C}_{1}\right)$ and $0.92 \mathrm{~h}\left(\mathrm{C}_{2}\right)$ for stage 2 . These values agree quite well with those estimated using the differences between the arrival time of the perturbation at the two stations, $0.93 \mathrm{~h}$ and $0.70 \mathrm{~h}$ for stages 1 and 2 respectively (see Figs. 2a and 3a). Considering the small difference of the calculated celerity between the two stages, a more similar time difference between the arrival times of the internal wave should be expected. We think that this difference may be explained by the differences in the current profile of the internal waves found in each stage. It should be noted that current profiles closer to the observations of the internal waves indicate an upper-layer current moving counter to and coincident with the propagation direction, respectively, in stages 1 and 2 .

\section{Origin of the short-period oscillations in salinity records: large-amplitude internal waves coming from the Camarinal Sill}

The visual evidence for the arrival at the Bay of Algeciras of refracted large-amplitude internal wave fronts, proceeding from the Camarinal Sill region (see Fig. 7) provides a likely cause for the salinity oscillations recorded at the measurement stations.

Following Vázquez et al. (2008), once these internal waves form at the Camarinal Sill, they get trapped on the lee side of the Sill because critical or supercritical conditions are established over this topographic feature. The instantaneous internal Froude number for continuous stratification (Hibiya, 1986; Vázquez et al., 2008) is customarily used to characterize the hydraulic conditions of the flow:

$F(t)=U(t) / c$

where $U(t)$ is the instantaneous barotropic current; and $c$ is the linear phase speed (phase speed) of the first baroclinic mode. Critical or supercritical conditions are then reached when $F(t) \geq 1$, while subcritical conditions correspond to $F(t)<1$.

Vázquez et al. (2008) found that the internal waves with largest amplitude were generated over the Camarinal Sill during periods 

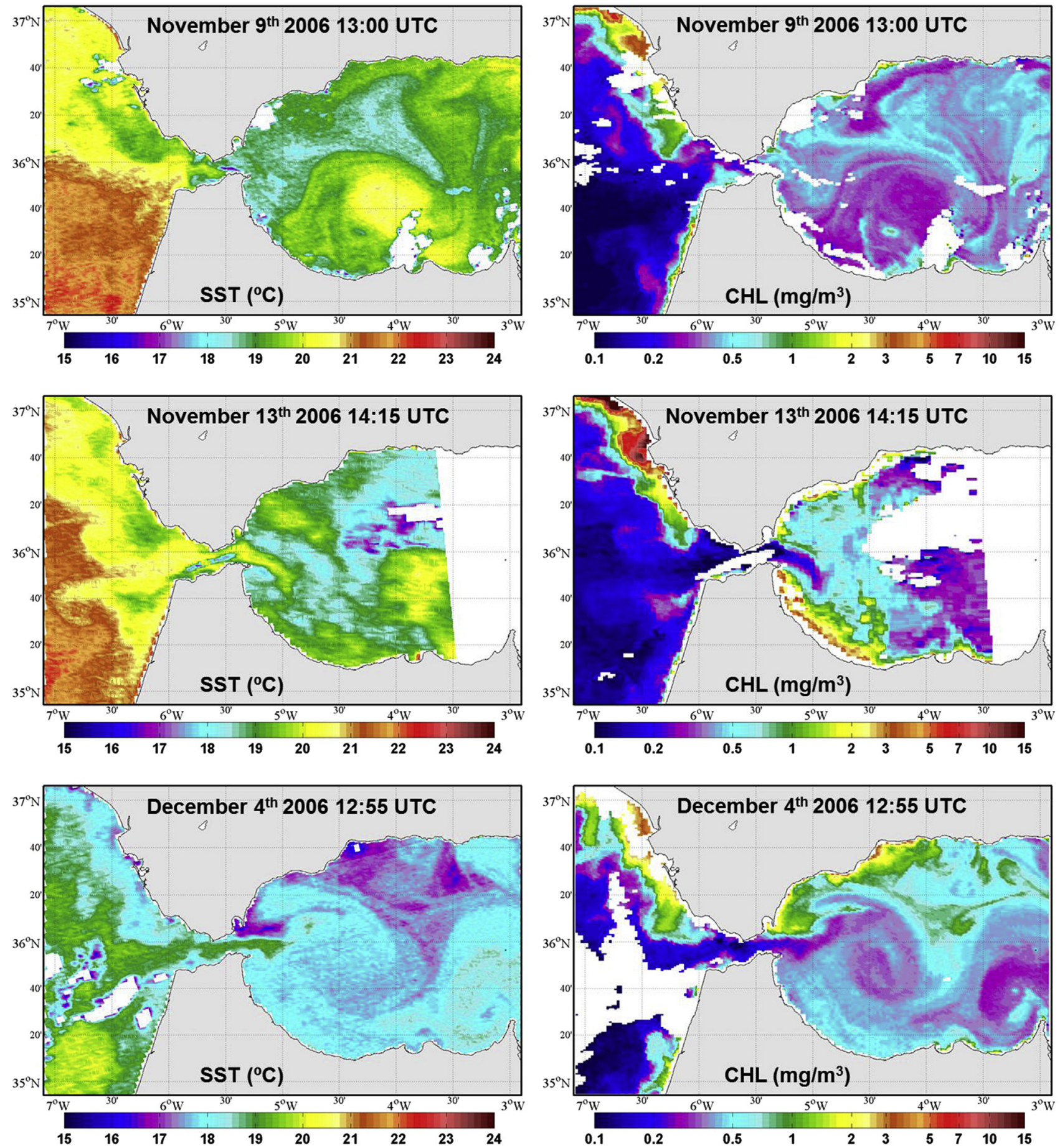

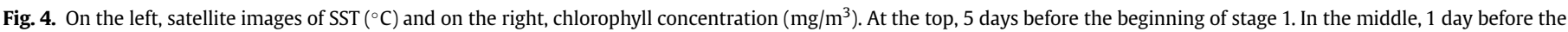
beginning of stage 1 . At the bottom, at the end of stage 2 .

of westward-flowing barotropic current only when $F(t) \geq 1$ over the Sill. These authors also found that critical conditions were established once the intensity of the barotropic flow reached $1 \mathrm{~m} \mathrm{~s}^{-1}$. It is deduced from this fact that the first mode phase speed over the Sill, for the stratification condition prevailing during the outflow, is roughly $1 \mathrm{~m} \mathrm{~s}^{-1}$. Accordingly, the condition for the generation of the internal waves may be replaced by $U(t) \geq 1 \mathrm{~m} \mathrm{~s}^{-1}$. This means that when the westward barotropic tidal currents over the Sill reach $1 \mathrm{~m} \mathrm{~s}^{-1}$, large internal undulations generated on the lee side of the Sill are blocked by the critical conditions upstream, and experience a notable increase in amplitude. Once the barotropic current intensity has weakened to less than $1 \mathrm{~m} \mathrm{~s}^{-1}$, subcritical conditions over the Sill are established and the internal waves are released, to begin their propagation towards the Alboran Sea.

Therefore, an empirical model based on the predictions of barotropic tidal current over the Camarinal Sill may be capable of predicting the time when large-amplitude internal waves are generated, and the time when they will be released and will propagate towards the Alboran Sea. 

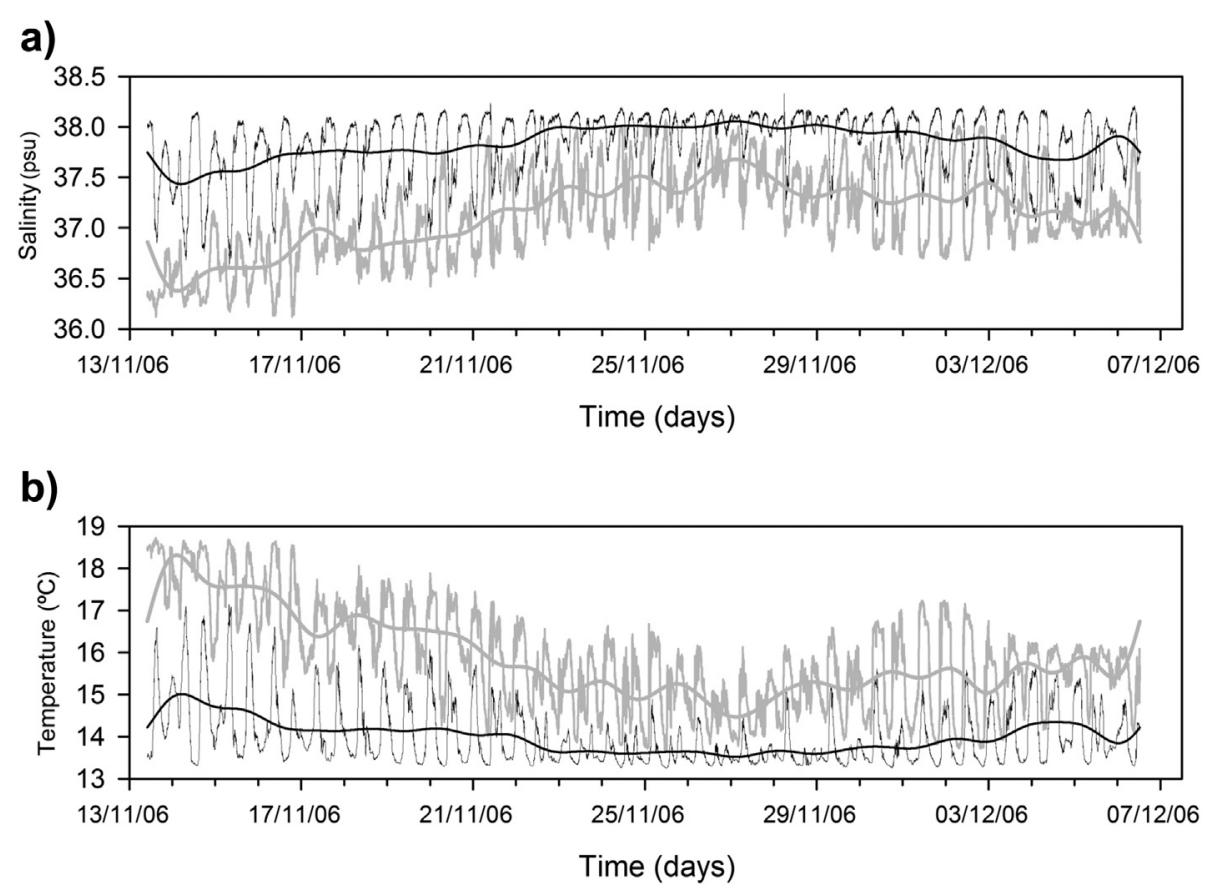

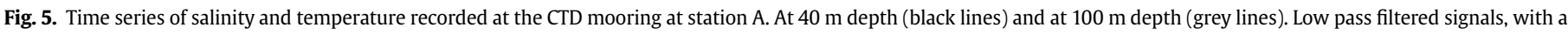
cut-off period of $33 \mathrm{~h}$, are superimposed.

In Fig. 7, three images illustrate the arrival of refracted largeamplitude internal wave fronts at the eastern side of the Strait of Gibraltar proceeding from the region of the Camarinal Sill. Those internal waves are released from the area where they are generated when subcritical conditions are reached over the sill, in other words, when the westward barotropic flow weakens to less than $1 \mathrm{~m} \mathrm{~s}^{-1}$ (Vázquez et al., 2008). The time difference between the arrival of the internal waves at the eastern side of the Strait and the predicted release of the waves from the Sill was $\sim 11 \mathrm{~h}$ for images $7 \mathrm{a}$ and $7 \mathrm{c}$ and $\sim 9.25 \mathrm{~h}$ for image $7 \mathrm{~b}$.

Figs. 8 and 9 show the predictions of barotropic tidal current velocity during neap (Fig. 8) and spring (Fig. 9) tide conditions within the observation period, along with the time series of high pass filtered salinity at station A. Such predictions have been made using the results from a harmonic analysis applied on a current velocity series recorded by an ADCP, moored over the Camarinal Sill during six months (see Vázquez et al. (2008) for more details). It can be seen that the predicted westward barotropic tidal current does not always reach $1 \mathrm{~m} \mathrm{~s}^{-1}$ during neap tides: this velocity is only reached alternately, with a basically diurnal periodicity. Nevertheless, maximum westward barotropic tidal currents exceed $1 \mathrm{~m} \mathrm{~s}^{-1}$ during all tidal cycles in spring tides.

Note that during the neap tide stage (Fig. 8) it seems that internal waves are received at station $A$, even when the empirical model does not predict critical or supercritical conditions during the westward phase of the tidal current over the Camarinal Sill. This finding may be explained by taking into account the modification of the hydraulic conditions over the Sill produced by subinertial flow variations, forced by atmospheric pressure fluctuations in the western Mediterranean (Vazquez et al., 2008). This mechanism is responsible for the activation of internal wave events during neap tides, and inhibition during spring tides. Vazquez et al. (2008) have demonstrated that an increase in the atmospheric pressure over the western Mediterranean provokes a westward flow that, added to the westward tidal current over the Camarinal Sill, is able to promote the occurrence of critical or supercritical conditions there, even when the maximum westward tidal current has an intensity of less than $1 \mathrm{~m} \mathrm{~s}^{-1}$. Hence, generation of the large-amplitude internal wave is possible, even when the mentioned empirical model (which only deals with tidal current) predicts subcritical conditions over the Sill. Following this result and considering Fig. 8a, it may be thought that the increase of atmospheric pressure taking place during the period between 2006/11/10 and 2006/11/16 could have activated the internal wave generation that was possibly produced during the westward tidal current phases that did not reach the intensity of $1 \mathrm{~m} \mathrm{~s}^{-1}$.

Given the conditions predicted over the Camarinal Sill, during the spring tide stage (Fig. 9), internal waves are expected to be generated at the Sill during each westward tidal current phase signal. This outcome is confirmed by the high frequency oscillations in the salinity record received at station A.

The signal of the internal waves, presumably generated at the Camarinal Sill, is detected at station A $8.34 \mathrm{~h}$ (on average) after the predicted release of the wave (taken as the moment when the predicted intensity of barotropic current is less than $1 \mathrm{~m} \mathrm{~s}^{-1}$ ); the observed time-lag oscillates between 8.5 and $10 \mathrm{~h}$ in neap tides, and between 8 and $9 \mathrm{~h}$ in spring tides. Those values compare fairly well with the time-lags shown in the images of Fig. 7. In addition, those values are also quite consistent with the mean phase speed of the internal waves between the Camarinal Sill and the eastern side of the Strait (Sánchez-Garrido et al., 2008; Vázquez et al., 2009). In Figs. 8 and 9 it is worth noting that, as found in Sánchez Garrido et al. (2008), the shorter the predicted travel time, the greater the maximum eastward tidal current. These results support the belief that internal waves recorded within the Bay could have been generated at the Camarinal Sill. However, from our results, the existence of internal wave activity from other origin within the Bay cannot be discounted. In fact, Fig. 7b shows a group of internal waves apparently being propagated westward from Gibraltar. Moreover, Watson and Robinson (1990) have reported the recording by a ship-based radar of internal waves being propagated northward, possibly generated from instabilities in the Atlantic Jet 
a)

EOF 1

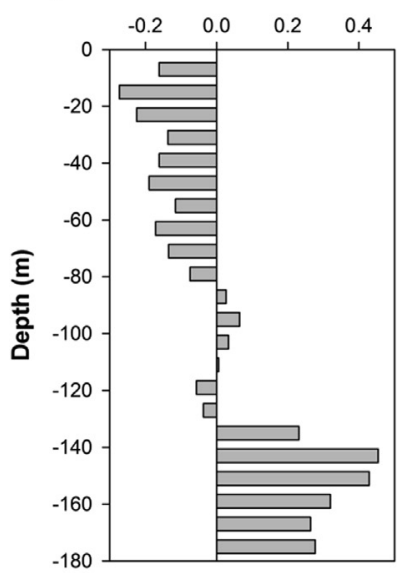

FRACTION OF EXPLAINED VARIANCE

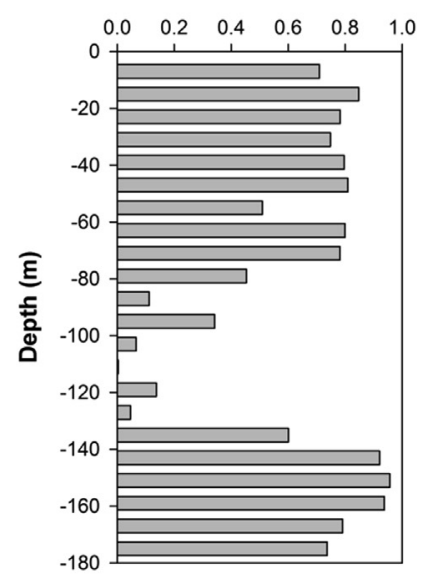

b) EOF 1

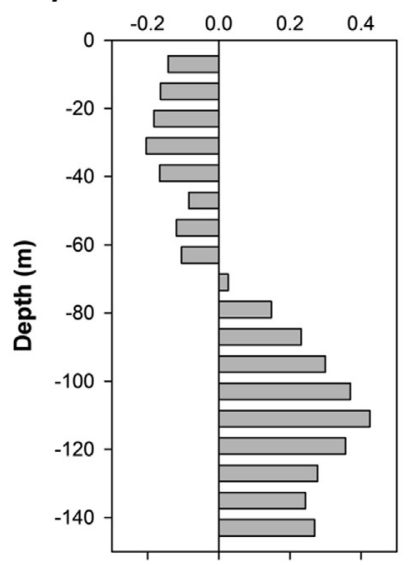

FRACTION OF EXPLAINED VARIANCE

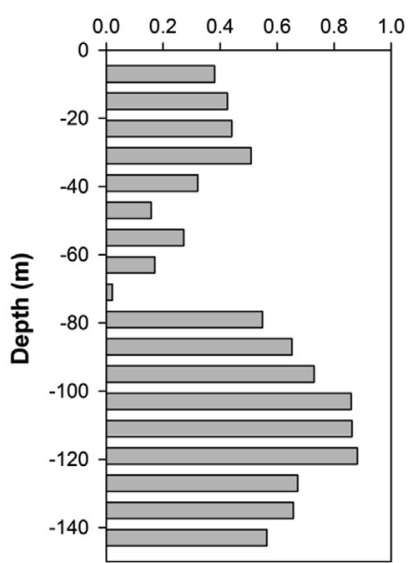

Fig. 6. Results from the EOF analysis performed on the current velocity profiles recorded by VM-ADCP at station $\mathrm{B}$, in order to isolate the internal wave signal in the south-north component of the current. a) Results for the neap tide stage. On the left, the distribution by depth of the spatial coefficients of the first empirical mode; and on the right, the fraction of variance explained by the first mode at each depth level; b) The same as a) for the spring tide stage.

front at the eastern side of the Strait. We think that the short period oscillations in high pass filtered salinity series, indicated by the vertical grey arrow on Fig. 3a, is likely to be a manifestation of waves of this type. Lastly, local generation of internal waves due to the interaction of the internal tide with the bottom topography of the Bay cannot be discounted. In any case, locally-generated internal waves at the head of the Bay do not seem have been present in the ADCP records obtained at station $B$, since the internal waves observed are propagated towards the head of the Bay.

\section{Mixing phenomena induced by the internal tide strain and the arrival of the internal waves}

It has been demonstrated that the arrival of large-amplitude internal waves in the Bay of Algeciras is a frequently recurring phenomenon. In this section we discuss the possible importance of those internal wave events for the occurrence of vertical mixing processes within the Bay. We think that the disturbance in the current velocity associated with the internal waves may significantly increase the vertical shear of the horizontal current, which

may lead, in turn, to the occurrence of vertical mixing in the water column.

Returning to the density profiles obtained at station B, shown in Figs. 2 and 3, we can observe that step-like structures seem to appear once internal waves have passed by the site: see, for instance, the profiles corresponding to casts $C_{1}, C_{2}, C_{3}$ and $C_{5}$ of stage 1 . This last cast offers the best evidence to link the step-like structures with the internal waves. Note that, in the previous cast (cast $\mathrm{C}_{4}$ ), step-like structures are absent whereas they appear clearly in the cast $C_{5}$ once the internal wave signals have been recorded at the station. Note also that density steps found in cast $C_{1}$ are still present in cast $C_{2}$ about $2 \mathrm{~h}$ later. From this observation, it is deduced that step formation phenomena may be extended to a relatively large area within the Bay, since advected step-like structures time. Once passing the measurement station lasted for a relatively long interval of the step-like structure is formed, a restratification of the water column is prevented by the action of the vertical shear of velocity, provided the latter is high enough to provoke subcritical values of $R_{i}$. This is a plausible explanation of why such structures may be maintained for relatively long timeintervals.

In addition to the effect of the internal-wave-generated vertical shear, another factor to take into account is the contribution of internal tide strain to the weakening of the density stratification within the pycnocline. It is known that the interaction between these two phenomena (strain and vertical shear) is important in triggering the diapycnical mixing processes (Carter and Gregg, 2002; Kunze et al., 2006). This last issue will be assessed in the following subsection.

\subsection{Role of the internal tide strain in the weakening of density stratification}

To assess the effect of the internal tide strain we have fitted each density profile, obtained at station $B$, to a linear combination of the vertical dynamical modes obtained from the solution of the SturmLiouville problem given by Equation (3). The $N(z)$ profile used has been obtained for a mean density profile computed by averaging the five profiles taken at each station over a semidiurnal tidal cycle. Once the vertical modes $\widehat{\psi}_{n}(z)$ are computed, density profiles may expressed in terms of these modes as

$\rho_{m}\left(z_{i}, t\right)=\rho_{0}\left(z_{i}\right)+\frac{\rho_{0}\left(z_{i}\right)}{g} \sum_{n=1}^{M} \gamma_{n}(t) \Gamma_{n}\left(z_{i}\right)$

where $\left.\rho_{0(z i}\right)$ is the time-averaged density profile; $z_{i}$ is the vertical coordinate of the density observations; $M$ is the number of modes considered; $\Gamma_{n}\left(z_{i}\right)=N^{2}\left(z_{i}\right) \widehat{\psi}_{n}\left(z_{i}\right)$; and $\gamma_{n}(t)$ are the timedependant coefficients determined by the least squares fit to the observed profiles at the different times of the CTD casts. Hereinafter, we will assume that, once the coefficients $\gamma_{n}(t)$ have been determined, the strain effects of the internal tide on the density profiles will be adequately reproduced through Equation (4).

Shown in Figs. 10 and 11, for the two stages respectively, are the vertical functions $\Gamma_{n}(z)$ for the first three baroclinic modes corresponding to the time-averaged density profile shown on the right. Shown below are the synthesized density profiles on the basis of Equation (4) superimposed on the observed profiles, for the CTD casts available in the two measurement stages. Also shown are the synthesized $N^{2}(z)$ profiles, at the bottom.

We begin by describing the results corresponding to the neap tide stage (Fig. 10). In cast $C_{1}$ it can be seen that the reconstruction of the density profile in terms of the dynamical modes resembles fairly well the step-like structures of the observed profile, although 
a) 2004 June $3^{\text {th }} 12: 21 \mathrm{GMT}$

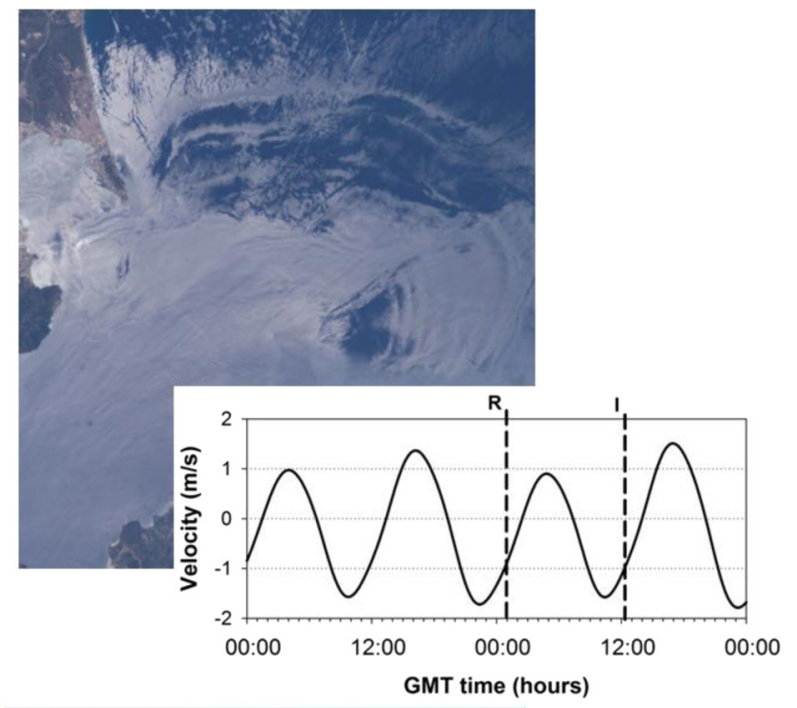

b) 2003 November $12^{\text {th }} 11: 00 \mathrm{GMT}$

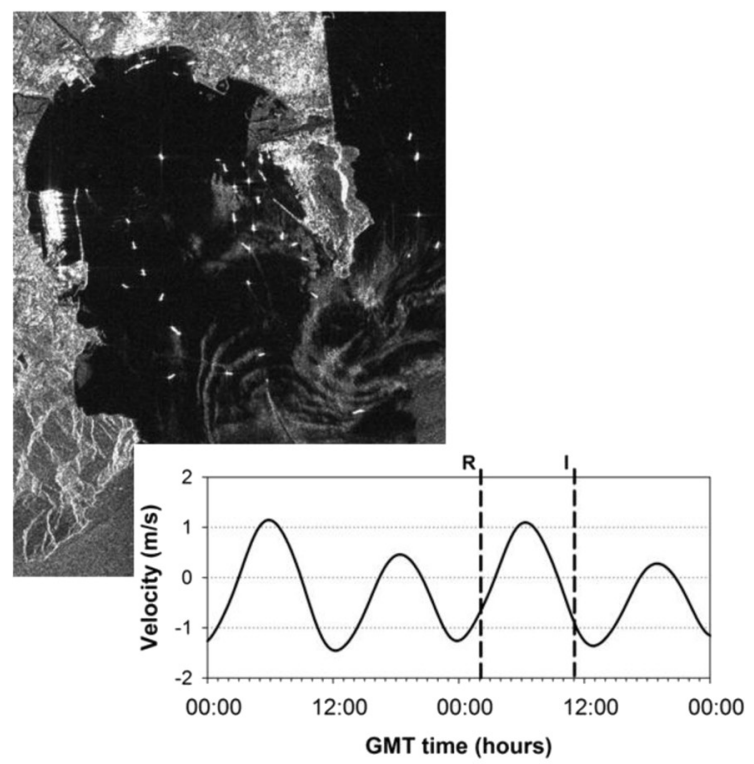

c) 2008 August $24^{\text {th }} 16: 00 \mathrm{GMT}$
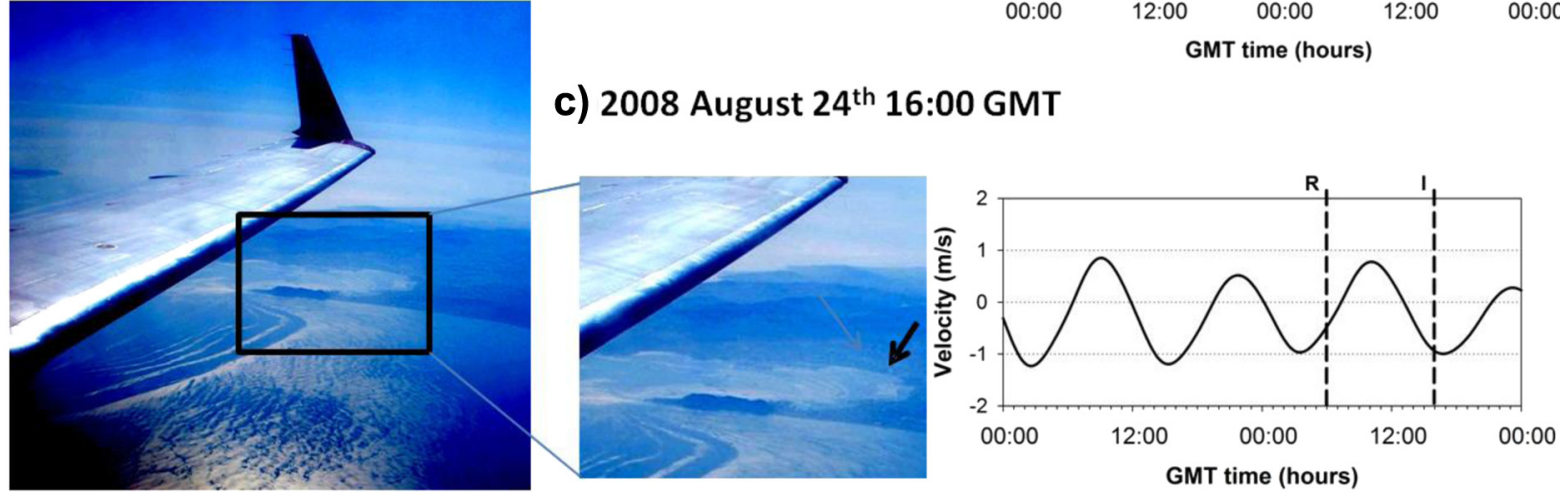

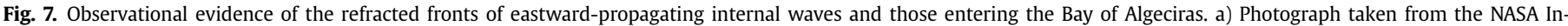

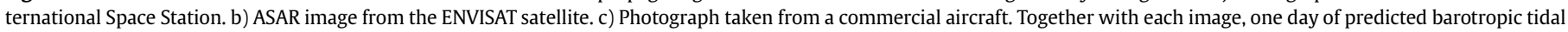

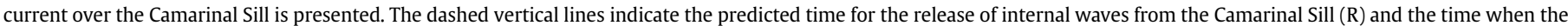
corresponding image was taken (I), respectively.

the observed $N^{2}(z)$ (Fig. 10d) shows a greater weakening of the stratification than that generated by the fitting to vertical dynamical modes. So it is quite likely that those structures were, at least originally, occasioned by the internal tide strain. However, once the density stratification is weakened by the strain effect in a given portion of the water column, the vertical mixing processes induced by vertical shear of the horizontal velocity are more prone to occur. On this point, it is worth noting the internal waves that passed the station during cast $C_{1}$, which could have contributed to the occurrence of vertical mixing within the density step that previously could have been formed by the internal tide strain. In cast $C_{2}$, we can see that the synthetic density profile fails to resemble the steplike structures remaining in the observed profile. This result indicates that now, such step-like structures cannot be explained in terms of the internal tide strain, even when they were primarily triggered by that effect. Note that the density step located about $50 \mathrm{~m}$ deep is maintained during casts $C_{3}$ and $C_{4}$, whereas such structures do not seem to be explained by the internal tide strain. Finally, in cast $C_{5}$, the synthetic density profile again matches fairly well the observed profile; this suggests that now the existing steplike structures could have been formed by the strain effect.

As a general rule, during the spring-tide stage (Fig. 11), step-like structures are less thick than those found in stage 1 . In cast $C_{1}$ the synthetic density profile fits very well the observed profile; this indicates that observed step-like structures may be explained basically in terms of the internal tide strain. However, in cast $C_{2}$ clear density steps can be seen just above $100 \mathrm{~m}$ deep and below $50 \mathrm{~m}$ deep; these are not explained by the synthetic density profile. This idea is also supported by the comparison between the synthetic and observed $N^{2}(z)$ profiles. Therefore, it seems that these density steps could be formed by vertical mixing episodes possibly preceded by a weakening of the stratification due to the internal tide strain. It is worth noting that internal waves pass by the station just during the performance of cast $C_{1}$ (see Fig. 3), which could favour the occurrence of vertical mixing within the density steps. We will return to this idea in the next section. In cast $C_{3}$, the density steps mentioned evolve, changing their depth and thickness; and finally in casts $C_{4}$ and $C_{5}$ a stratification of the density seems to take place and in these cases, step-like structures are fairly well explained in terms of the internal tide strain.

\subsection{Gradient Richardson number computations}

To predict when vertical mixing is expected to occur, it is customary to use the gradient Richardson number, which is defined as:

$R_{i}=\frac{N^{2}}{\left(\frac{\partial u}{\partial z}\right)^{2}}$ 
a)
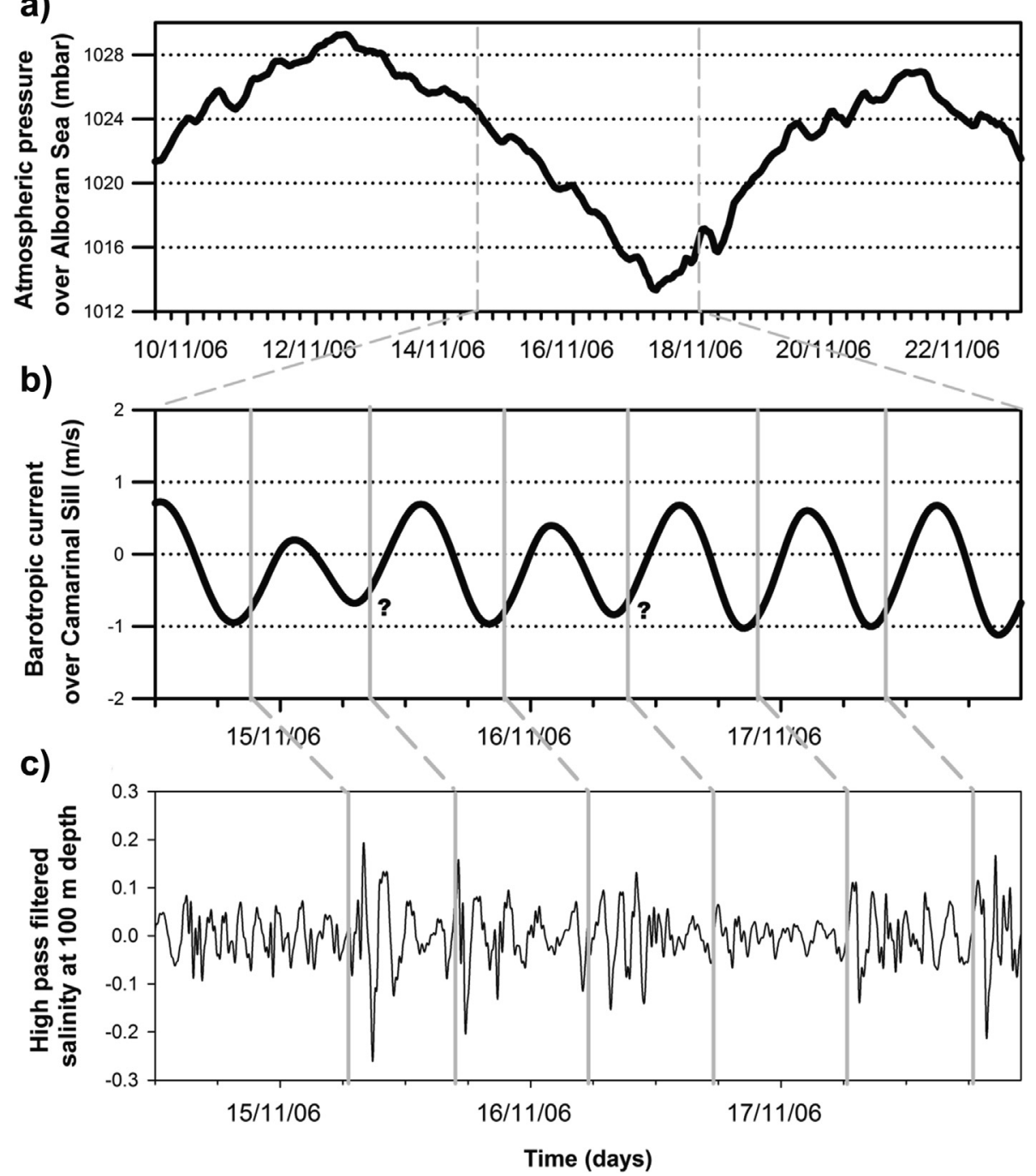

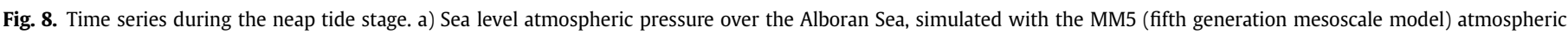

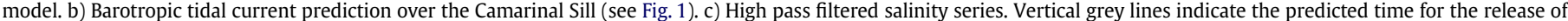

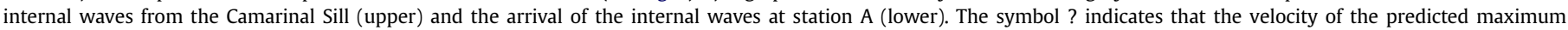
westward tidal current over Camarinal Sill did not reach $1 \mathrm{~m} \mathrm{~s}^{-1}$.

where $N$ is the buoyancy frequency profile in the undisturbed state; $u$ is the south-north current velocity; and $z$ is the upward vertical co-ordinate. However, the correct interpretation of these measurements made in field studies is usually a difficult task. An example of the types of difficulty one can find is when the profile of this parameter is calculated some time after the water column has undergone a vertical mixing event, when the motive of the research is just to identify the conditions prior to the occurrence of that event. For instance, if $R_{i}$ is computed over the span of a recentlymixed portion of the water column, a little vertical shear of the horizontal velocity may be enough to produce subcritical values of $R_{i}$. In such a case, these values may be indicating correctly the propensity of that portion of the water column to undergo vertical mixing, but they do not provide any information about the conditions that gave rise to the first mixing event.

The case commented is precisely the one we face in our analysis. Looking at the density profile corresponding to cast $C_{1}$ of stage 1 (Fig. 2), the presence of step-like structures in the profile is clear. However, we are not able to inquire if that structure has been originated by a vertical mixing event, because the previous density and ADCP profiles that would permit the calculation of $R_{i}$ at the moment in time prior to the mixing event are not available. All that we can do in this situation is to compute the $R_{i}$ profiles using the available current density and ADCP profiles considering that they may have been affected by previous vertical mixing processes.

In the next part we will establish that the vertical shear throughout a given water column is given by the combined effect of two contributory factors: (1) the local internal tide; (2) the internal waves coming from the Camarinal Sill that penetrate into the Bay. To investigate the separate contribution to the velocity shear made by each of the two factors, we will establish first that the vertical shear induced by the internal tide is that computed using the timeaveraged velocity profiles throughout the time spent during each cast (see Table 1). Secondly, the added contribution to the vertical shear due to the internal waves may be estimated by comparing the actual vertical shear to that due uniquely to the internal tide.

On the basis of these separated current velocity profiles, we have computed the $R_{i}$ profiles corresponding to the local internal tide and the incoming internal waves. These profiles, for stages 1 (neap tide) and 2 (spring tide) respectively, are shown in Figs. 12 

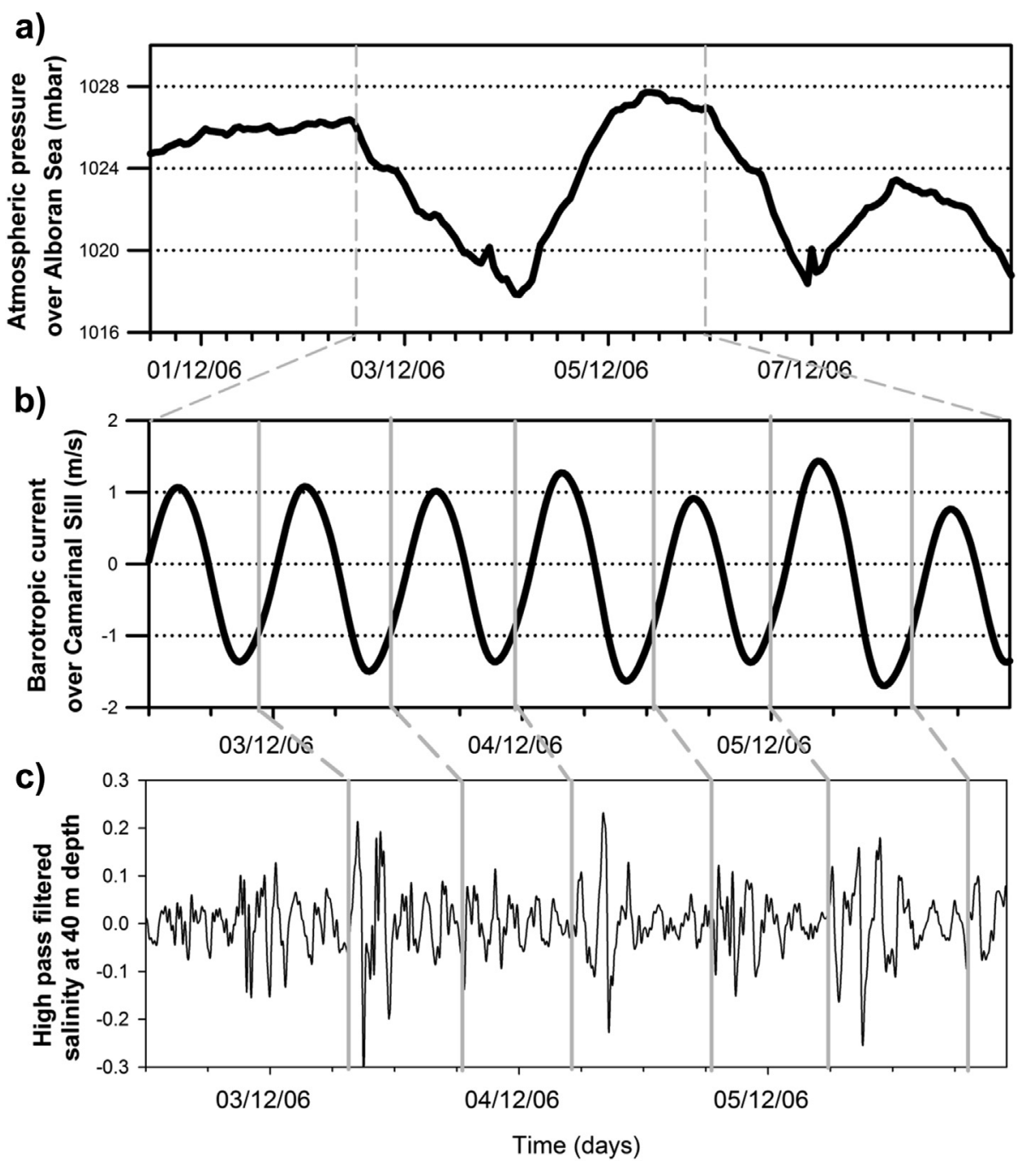

Fig. 9. The same as Fig. 8, but for the spring tide stage.

and 13 . In both stages the profiles correspond to the cast $C_{1}$ shown in Figs. 2 and 3.

During neap tide (Fig. 12), the available density profile shows clear step-like structures, which may have been originated by previous vertical mixing processes. Therefore, our $R_{i}$ computations will be used to assess the propensity of the water column to undergo vertical mixing events under the conditions given by the cited step-like structures. It can be seen that the internal tide current only produces subcritical $R_{i}$ at depths of around $150 \mathrm{~m}$, while $R_{i}$ profiles induced by the internal waves show near-subcritical values at a depth of about $125 \mathrm{~m}$ and in the upper region of the water column (between the surface and $25 \mathrm{~m}$ depth). However, if the combined effect of tidal plus internal wave currents is considered, some near-subcritical zones appear in the $R_{i}$ profiles within the depth range where the pycnocline is located.

This result may be explained by examining, in Fig. 12b, the current velocity profiles $\mathrm{P} 1$ and $\mathrm{P} 2$, coincident, respectively, with the passage of the depression and the elevation of the internal wave described in Fig. 2b. In P1 the vertical shear of tidal currents is opposite to the shear induced by the internal wave throughout the major part of the range of depths analyzed, and this gives rise to a reduced vertical shear and higher $R_{i}$ values in those regions of the water column. On the other hand, in P2 the situation is the reverse; now the vertical shear induced by the tidal currents and the internal wave reinforce each other, and this results in the appearance of zones with near-subcritical $R_{i}$ values, in which vertical mixing processes may be prone to occur.

During spring tide (Fig. 13), the available density profile also shows clear step-like structures. The tidal current produces nearsubcritical $R_{i}$ values at a depth of about $105 \mathrm{~m}$, while the added contribution of the internal wave-induced current produces nearsubcritical $R_{i}$ values at a depth of about $65 \mathrm{~m}$. The combined effect of tidal and internal wave-induced currents is capable of extending the region of near-subcritical $R_{i}$ values from 100 to $60 \mathrm{~m}$, thus making possible vertical mixing within the pycnocline.

We next examine the current velocity profiles P1 and P2, coincident, respectively, with the passage of the elevation and the depression of the internal wave shown in Fig. 3b. In P1 it can be observed (Fig. 13b) that the vertical shear produced by the tidal current is opposite to that produced by the internal wave; this leads to a reduced vertical shear and high $R_{i}$ values. In P2, on the other hand, the two contributions to the vertical shear match very well with each other, and this gives rise to zones within the pycnocline in which vertical mixing is prone to occur.

Therefore, independently of whether or not the observed steplike structures were initially induced by the internal tide strain, it seems that the subsequent vertical mixing processes following the step-like formation are aided by the effect of the short period 

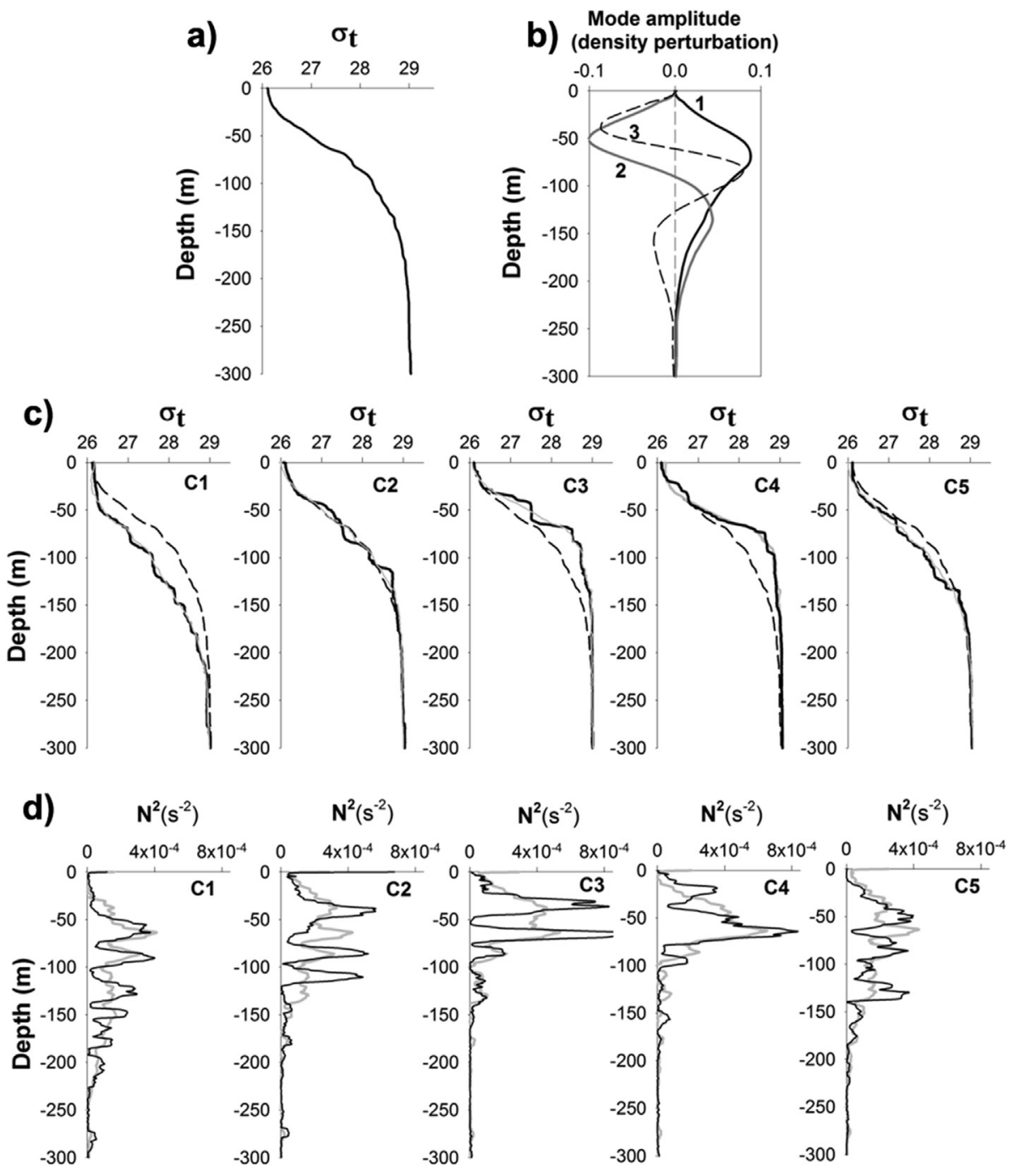

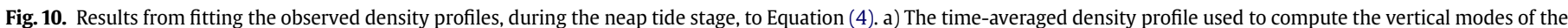

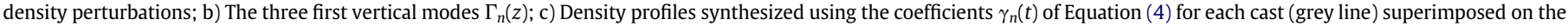

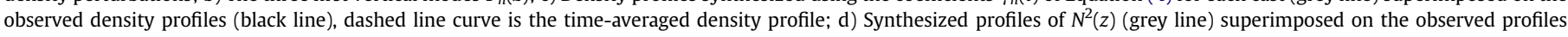
(black line).

internal waves coming from the Camarinal Sill area, and these processes seem to be responsible for the subcritical character of the water column in the depth range from 25 to $125 \mathrm{~m}$.

\subsection{Energy considerations in respect of the density step formation}

In this section we try to complement, in the framework of the turbulent kinetic energy transformations, the results reported in Section 4.2 in order to support the involvement of the short period internal waves from the Camarinal Sill region in the triggering of the vertical mixing phenomena within the Bay. First of all, we will introduce the following assumptions:

(1) It is assumed that the density profile prior to the mixing event may be approximated by an adequately smoothed profile that, as far as possible, leaves equal portions of the step above and below it. This assumption may be reasonable if the mixing event that gave rise to the density step was triggered by a Kelvin-Helmholtz instability (Kundu, 1990). Fig. 14 illustrates this approach;

(2) Regarding the velocity profiles, it is assumed that vertical shear of the horizontal velocity throughout the portion of the water column occupied by the density step was, in the situation prior to its formation, greater than the shear observed when the density step stands formed (see Fig. 14). This is a logical consequence of the conversion from kinetic to potential energies involved in the vertical mixing processes. Accordingly, the values of $R_{i}$ calculated with the smoothed density profile, over the length of that portion of the water column occupied by the density step, may be understood as an underestimate of this parameter in the situation prior to the formation of the density step.

Now, following the assumption that density steps are formed from a $\mathrm{K}-\mathrm{H}$ instability, a simple analytical framework can be established to analyze the phenomenon in terms of the involved energy transfer. Following Winters et al. (1995), when a density step is formed, an increase of potential energy occurs in the mixed portion of the water column, and it is known that such an increase of potential energy is supplied by part of the turbulent kinetic energy lost by the sheared flow which triggered the initial instability. This energy transfer is expressed as:

$\Delta E_{p}=-\varepsilon \Delta E_{k}$ 
a)

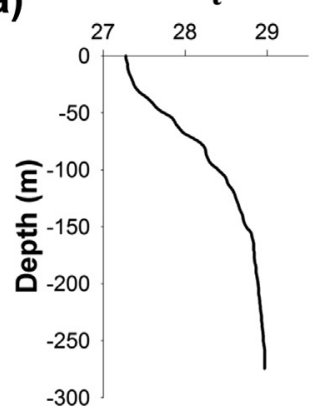

Mode amplitude

b) (density perturbation)

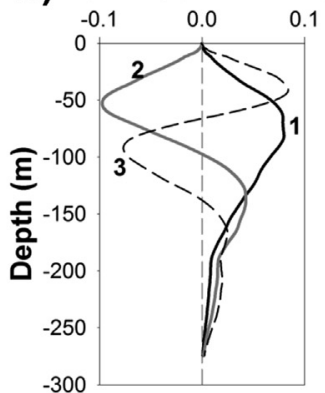

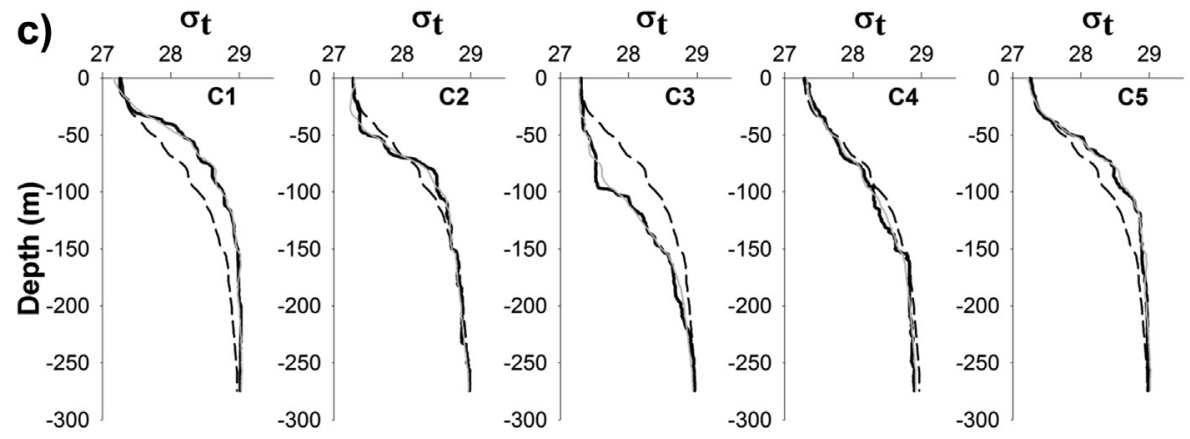

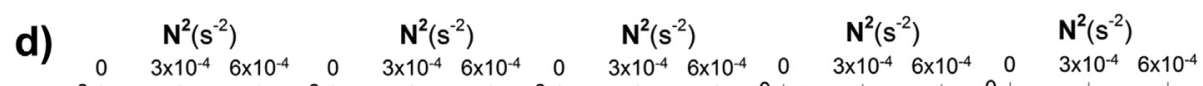

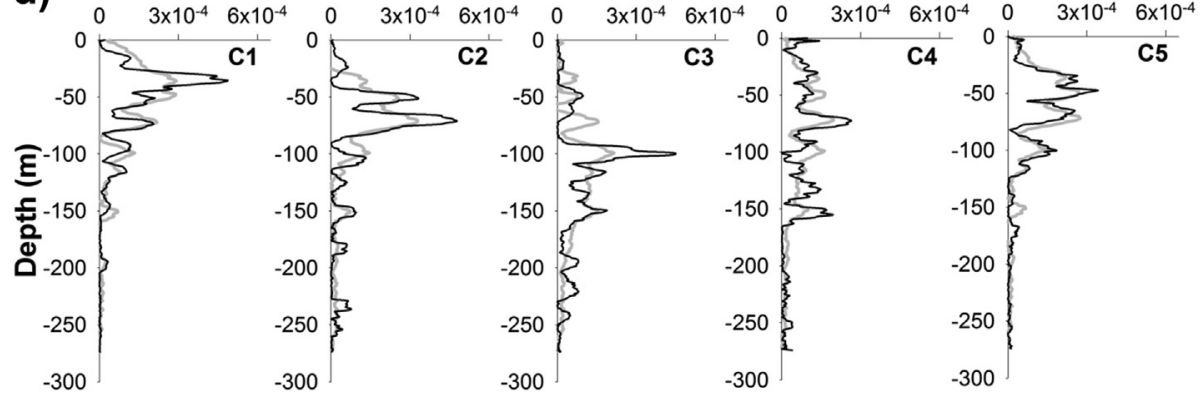

Fig. 11. The same as Fig. 10, but for the spring tide stage.

where $\varepsilon$ is the mixing efficiency, i.e. the ratio of the available kinetic energy to be used in changing the potential energy of the water column after mixing processes have taken place (De Silva et al., 1999; Peltier and Caulfield, 2003).

The change of kinetic and potential energies before and after the occurrence of the vertical mixing, that gives rise to the density step, may be characterised using the scheme of Fig. 14. Then, assuming, for the situation before the mixing, a linear variation for density and velocity throughout a given stratified portion of the water column

$u(z)=u_{2}+\frac{\left(u_{1}-u_{2}\right)}{\delta_{m}} z$

$\rho(z)=\rho_{2}+\frac{\left(\rho_{1}-\rho_{2}\right)}{\delta m} z$

where sub-indices 1 and 2 stand for the values of density and velocity at the top and bottom of the stratified and sheared portion of the water column.
After the mixing has happened, the following linear variation of the velocity throughout the mixed portion of the water column is assumed:

$u(z)=u_{m 2}+\frac{\left(u_{m 1}-u_{m 2}\right)}{\delta_{m}} z$

while density is assumed to take a uniform value $\rho_{m}$. Then we can arrive at the following expressions for the depth-integrated potential and kinetic energy before the mixing event throughout the step thickness $\delta_{m}$ :

$E_{k}^{b}=\frac{1}{2} \int_{0}^{\delta_{m}} \rho(z) u^{2} \mathrm{~d} z=\frac{\delta_{m} \rho_{m}}{6}\left(u_{1}^{2}+u_{1} u_{2}+u_{2}^{2}\right)$

$E_{p}^{b}=\int_{0}^{\delta_{m}} g \rho(z) z \mathrm{~d} z=\frac{1}{6} g\left(2 \rho_{1}+\rho_{2}\right) \delta_{m}^{2}$

which, for the situation after the mixing event, will read as: 
a)
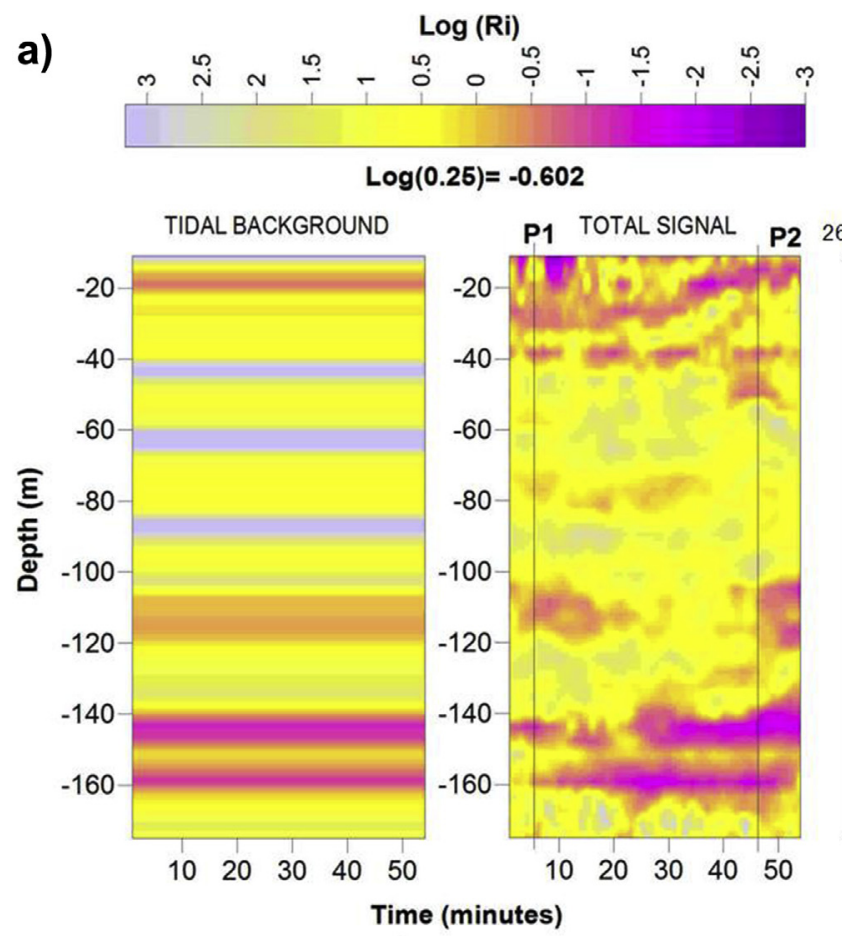

$2 \begin{array}{llllll}26.0 & 26.5 & 27.0 & 27.5 & 28.0 & 28.5\end{array}$

b)
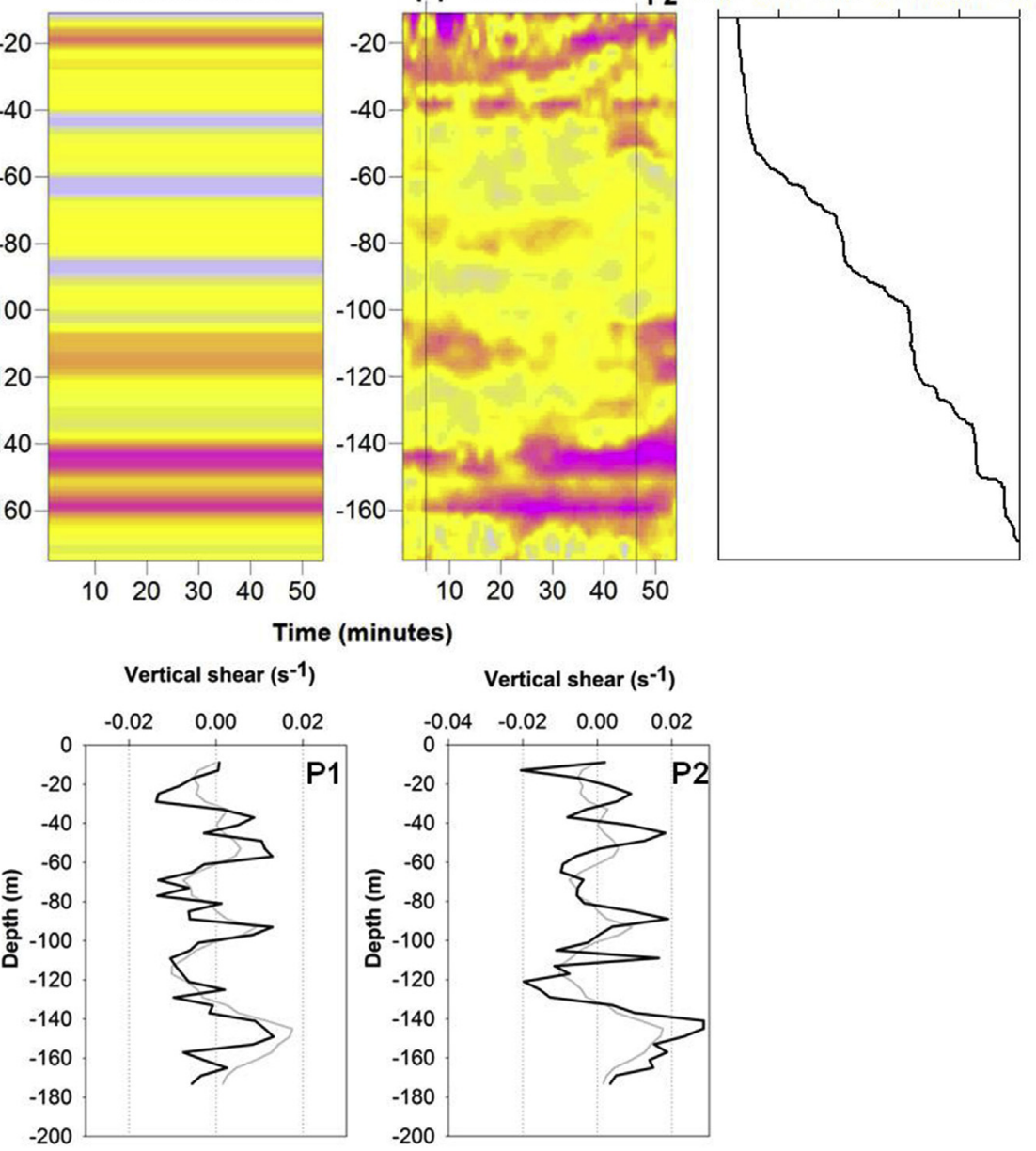

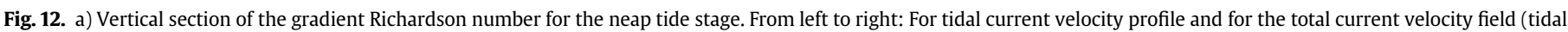

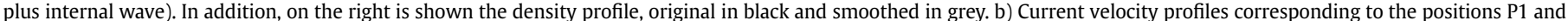

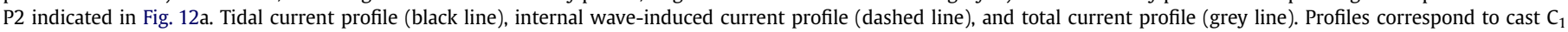
shown in Fig. 2.

$E_{k}^{a}=\frac{1}{2} \int_{0}^{\delta_{m}} \rho(z) u^{2} \mathrm{~d} z=\frac{\delta_{m} \rho_{m}}{6}\left(u_{m 1}^{2}+u_{m 1} u_{m 2}+u_{m 2}^{2}\right)$

$E_{p}^{a}=\int_{0}^{\delta_{m}} g \rho(z) z \mathrm{~d} z=\frac{g \rho_{m} \delta_{m}^{2}}{2}$

Note that the origin of the co-ordinate $z$ is taken as the bottom of the stratified portion of the water column under consideration. Thus the changes in kinetic and potential energies between the two situations may be expressed as:

$\Delta E_{p}=E_{p}^{a}-E_{p}^{b}=\frac{g \delta_{m}^{2}}{12}\left(\rho_{2}-\rho_{1}\right)$

$\Delta E_{k}=E_{k}^{a}-E_{k}^{b}=\frac{\delta_{m} \rho_{m}}{6}\left[u_{m 1}^{2}+u_{m 1} u_{m 2}+u_{m 2}^{2}-u_{1}^{2}-u_{1} u_{2}-u_{2}^{2}\right]$ and finally, considering that velocities at the top and bottom of the mixed portion of the water column may be expressed as

$$
\begin{aligned}
& u_{1}=\bar{u}+\Delta u \\
& u_{2}=\bar{u}-\Delta u \\
& u_{m 1}=\bar{u}_{m}+\Delta u_{m} \\
& u_{m 2}=\bar{u}_{m}-\Delta u_{m}
\end{aligned}
$$

where $\Delta u=\left|u_{1}-u_{2}\right| / 2 ; \Delta u_{m}=\left|u_{m 1}-u_{m 2}\right| / 2$ and over-bar stand for the mean value of velocity throughout the mixed water column portion, substitution of the last expressions into Equation (4), after considering that the mean velocity in the mixed portion of the water column remains unchanged (i.e. $\bar{u}_{m}=\bar{u}$ ), yields the following relationship: 
a)
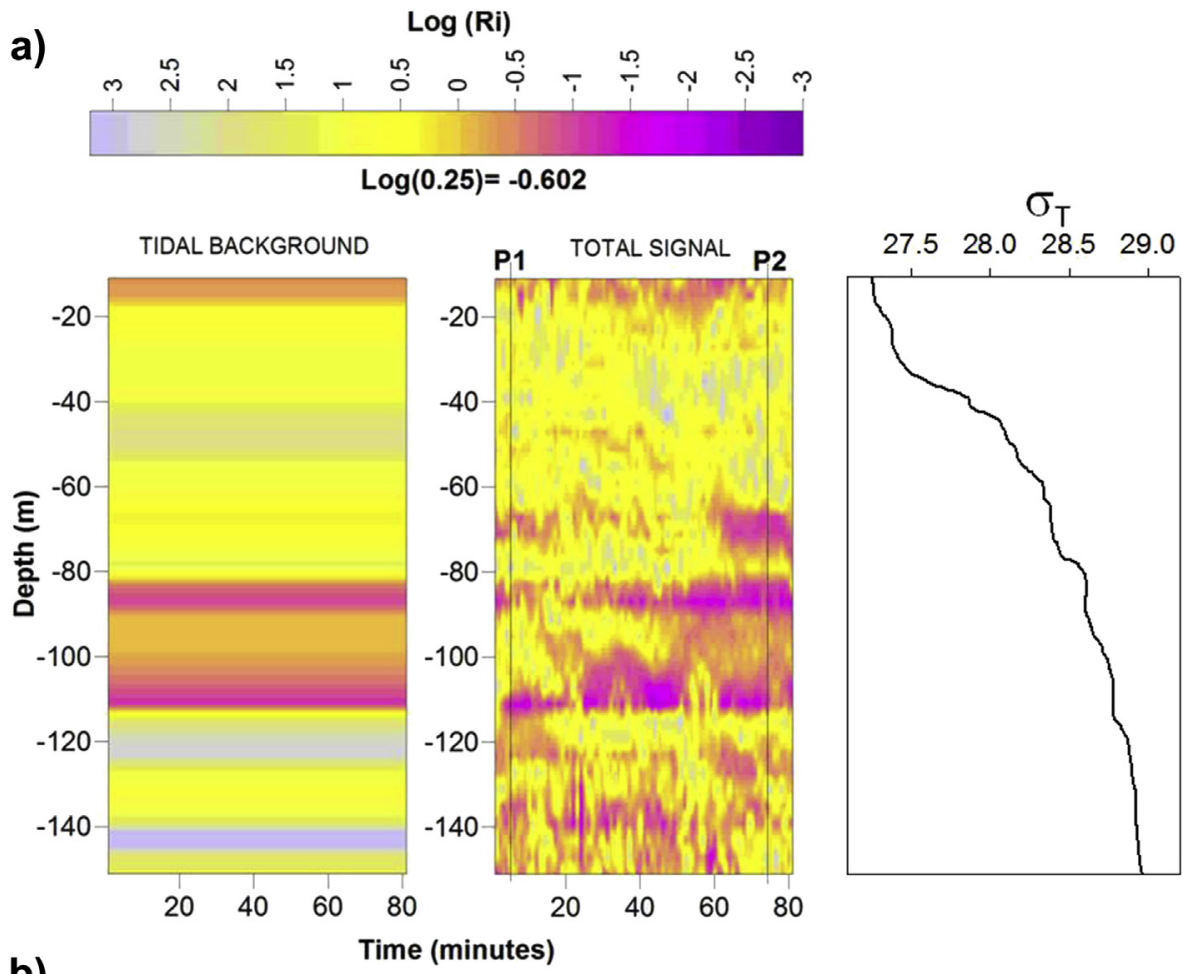

b)

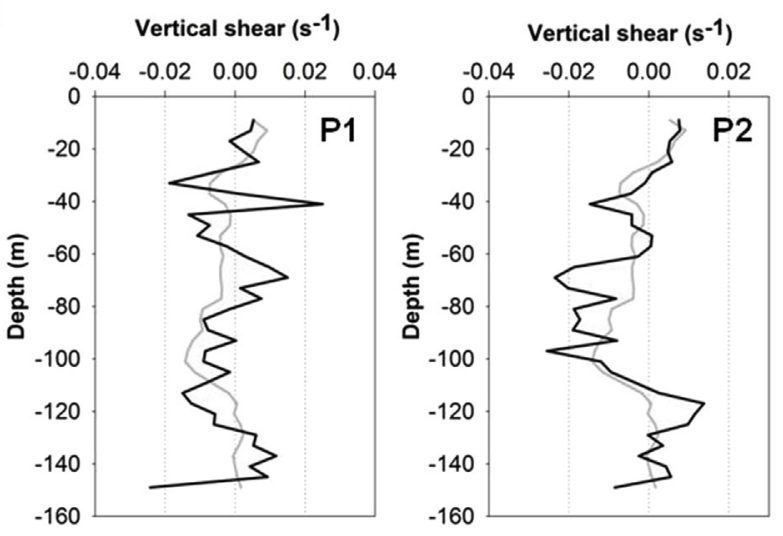

Fig. 13. The same as Fig. 12, but for the spring tide stage. Profiles correspond to cast $C_{1}$ shown in Fig. 3 .

$(\Delta u)^{2}=\left(\Delta u_{m}\right)^{2}+\frac{g \delta_{m}\left(\rho_{2}-\rho_{1}\right)}{2 \varepsilon \rho_{m}}$

By means of this relationship we can estimate the vertical shear of the horizontal velocity, $\Delta u / \delta_{m}$, needed to form a density step of thickness $\delta_{m}$.

Let us now apply Equation (8) to the density steps appearing in Fig. 15, where the density and current velocity profiles corresponding to the casts $C_{1}$ of stage 1 and $C_{2}$ of stage 2 are shown. These profiles have been chosen because the casts have been performed just after an internal wave event, which could be the factor responsible for the step-like structures, has been recorded at station B (Figs. 2 and 3).

Note that the smoothed density profiles represent an attempt to approximate the stratification conditions prior to the mixing event. Assuming that these smoothed profiles follow a linear variation throughout the portion of the water column that later will be occupied by the step, we can get an estimate of the density values at the top and bottom of the thickness of the step $\delta_{m}$ deduced from the original profiles, and a value for the $\varepsilon$ that, following Peltier and

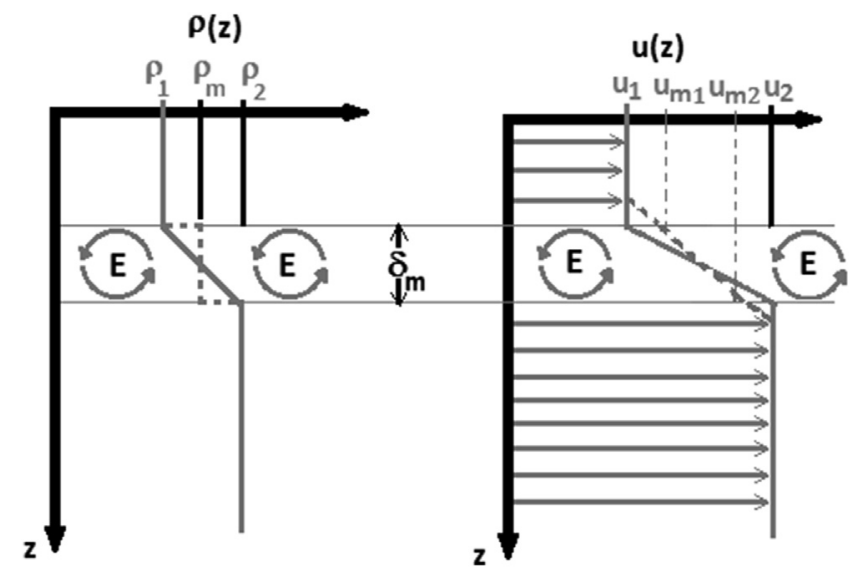

Fig. 14. An illustration of the vertical mixing process resulting in a density step formation triggered by a Kelvin-Helmholtz instability. 
a)

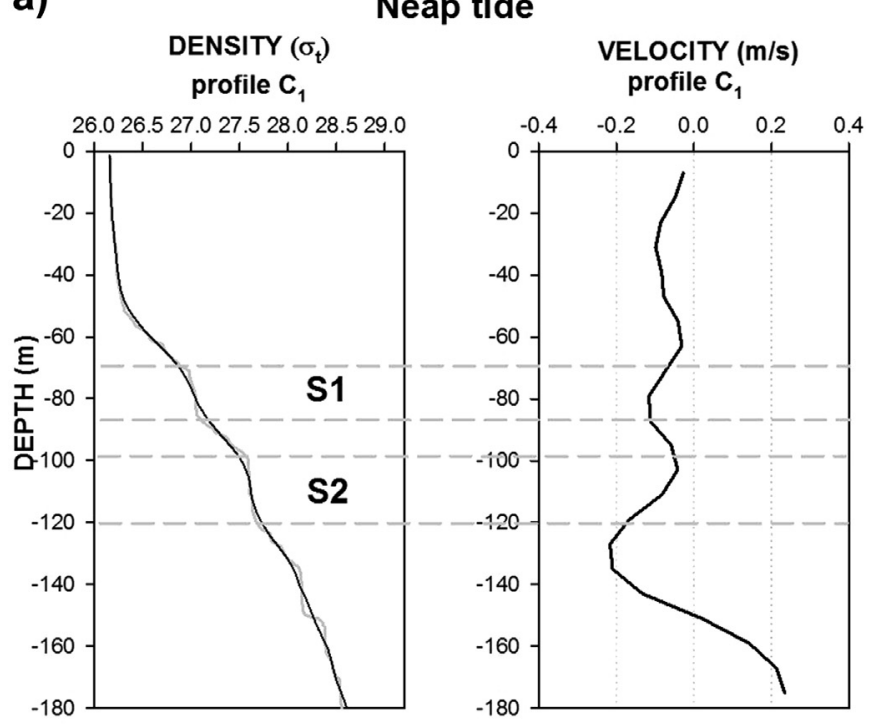

b)

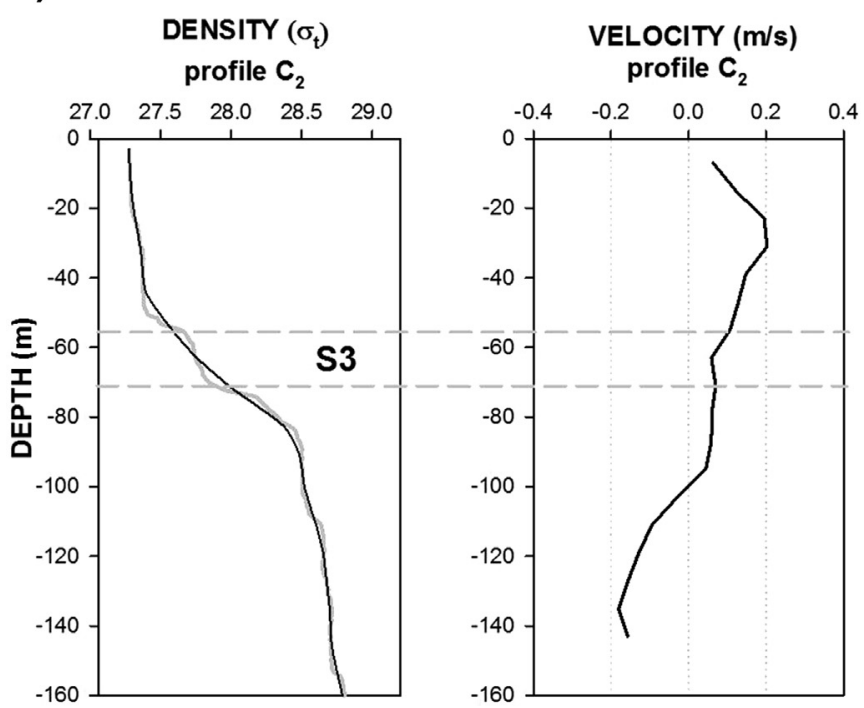

Fig. 15. Density and ADCP profiles in which density steps were present. a) Cast $C_{1}$ of stage 1. b) Cast $C_{2}$ of stage 2 . Grey dashed horizontal lines demarcate the density steps to which reference is made in the text.

Caulfield (2003), may lie in the range $0.2-0.5$. In those profiles we have identified three density steps, referred to in the figures as $\mathrm{S} 1$, S2 and S3. Shown in Table 2 are the estimated vertical shear of velocity and the set of parameters used for its calculation.

\section{Table 2}

Estimates of the vertical shear of the velocity needed to form the density steps ( $\mathrm{S} 1$, S2 and S3) indicated in Fig. 15 using Equation (8).

\begin{tabular}{lllllll}
\hline $\begin{array}{l}\text { Density } \\
\text { step }\end{array}$ & \multicolumn{9}{c}{} & & \begin{tabular}{l}
$\varepsilon=0.2$ \\
\cline { 2 - 4 }
\end{tabular} & $\delta_{m}(\mathrm{~m})$ & $\begin{array}{l}\Delta u_{m} \\
\left(\mathrm{~m} \mathrm{~s}^{-1}\right)\end{array}$ & $\begin{array}{l}\left(\rho_{2}-\rho_{1}\right) \\
\left(\mathrm{Kg} \mathrm{m}^{-3}\right)\end{array}$ & $\begin{array}{l}\rho_{m} \\
\left(\mathrm{~kg} \mathrm{~m}^{-3}\right)\end{array}$ & $\begin{array}{l}\frac{\varepsilon=0.5}{\Delta u / \delta_{m}} \\
\left(\mathrm{~s}^{-1}\right)\end{array}$ & $\begin{array}{l}\frac{1}{\Delta u / \delta_{m}} \\
\left(\mathrm{~s}^{-1}\right)\end{array}$ \\
\hline S1 & 14.00 & 0.04 & 0.34 & 27.03 & 0.0256 & 0.0164 \\
S2 & 21.00 & 0.12 & 0.25 & 27.61 & 0.0179 & 0.0122 \\
S3 & 15.31 & 0.04 & 0.39 & 27.74 & 0.0234 & 0.0150 \\
\hline
\end{tabular}

We found that the estimated vertical shear of the horizontal velocity that could give rise to the steps is about $0.02 \mathrm{~s}^{-1}$ (for $\varepsilon=0.2$ ) and about 0.015 (for $\varepsilon=0.5$ ). This vertical shear represents a velocity change of $0.35 \mathrm{~m} \mathrm{~s}^{-1}$ (for $\varepsilon=0.2$ ) and $0.23 \mathrm{~m} \mathrm{~s}^{-1}$ (for $\varepsilon=0.5$ ), throughout a vertical distance of $17 \mathrm{~m}$ (roughly the averaged thickness of the steps). This is a value that could only be expected in our observations (see vertical shear values in Figs. 12 and 13) if a joint contribution to the shear from the local tidal forcing (strain and vertical shear induced by the internal tide) and internal waves is considered.

\section{Conclusions}

The present paper reports an analysis performed of the tidal and shorter-period dynamics in the Bay of Algeciras. The analysis has covered and compared two different periods; one during neap tide conditions and the other during spring tide.

Internal tide dynamics exhibits behaviour that is very different between neap and spring tide conditions. At neap tide, tidal current intensities reach maximum values at low and high tides, while minimum intensities are reached in the middle of the flood and ebb tides. In contrast, at spring tide the maximum tidal current intensity is reached $2 \mathrm{~h}$ after high tide. It is suggested that this difference in behaviour could be related to the significant increase in density that is experienced by the upper layer during the spring tide phase, which could modify the phase speed of the internal tide on the eastern side of the Strait and Bay of Algeciras. Such a density change seems to be related to the behaviour of the Atlantic jet entering the Alboran Sea; this was deflected towards the south during the whole measurement period, thus allowing a process of exchange between the inner waters of the Bay and the waters of the Alboran Sea.

Shorter-period dynamics seems to be dominated by the largeamplitude internal waves that penetrate the Bay proceeding from the Camarinal Sill region. The arrival times of these internal waves at the measurement stations within the Bay are in good agreement with the available predictive models and the observational evidence offered by ASAR satellite images, and photographs from aircraft and the NASA International Space Station.

Vertical mixing processes within the Bay depend on the interaction between the two dynamics: (1) internal tide and (2) short period internal waves. At least in the light of the data analyzed in this study, neither of the two dynamics is capable, by itself, of producing an effective vertical mixing in the pycnocline region. Similarly, the penetration of the mixing processes into the pycnocline, evidence for which is provided by the stepwise structures in the density profiles which are not explained by the internal tide strain, would not be possible without the participation of the internal wave dynamics.

The results obtained highlight the importance of taking into account the remote effects that processes generated in a given oceanographic region (in this case, large-amplitude internal waves generated over the Camarinal Sill) may have on the water mass dynamics of other regions (in this case, the Bay of Algeciras). Vigorous vertical mixing processes within the Bay seem to be induced by the joint effect of the local tidal dynamics and the largeamplitude internal waves originating from the region of the Sill that arrive at and penetrate into the Bay. Accordingly, any realistic mathematical model of the water circulation in the Bay must take account of the contribution to those mixing processes of the internal waves arriving from the Sill. While the case studied here concerns a very singular oceanic region, it is expected that similar examples could be found in many oceanic regions where energetic processes occurring in one very specific area may exert significant influence on another area located relatively remote from it. 


\section{Acknowledgements}

The present work has been funded partially by the following Research Projects: CTM2008-06421/MAR, 0419_TRADE_5_E, CTM2007-0408/MAR, P09-RNM-4547, RNM-7722, CTM 2010-20945/ MAR and CGL2008-04736. Photographs in Fig. 7a have been provided by the International Space Station of NASA. The ASAR image in Fig. 7b was acquired within the ENVISAT-CAT1-P1315 project. The photograph in Fig. 7c was kindly provided by Dr. José Manuel Gonzalez Vida.

\section{References}

Álvarez, Ó., González, C.J., Mañanes, R., López, L., Bruno, M., Izquierdo, A., GómezEnri, J., Forero, M., 2011. Analysis of short-period internal waves using waveinduced surface displacement: a 3D model approach in Algeciras Bay and the Strait of Gibraltar. Journal of Geophysical Research 116, C12033.

Armi, L., Farmer, D.M., 1988. The flow of Mediterranean water through the Strait of Gibraltar. Progress in Oceanography 21, 1-105.

Bruno, M., Mañanes, R., Alonso, J.J., Izquierdo, A., Tejedor, L., Kagan, B., 2000. Vertical structure of the semidiurnal tidal currents at Camarinal Sill, the Strait of Gibraltar. Oceanologica Acta 23 (1), 15-24.

Bruno, M., Vázquez, A., Gómez-Enri, J., Vargas, J.M., García-Lafuente, J.M., RuizCañavate, A., Mariscal, L., Vidal, J.M., 2006. Observations of internal waves and associated mixing phenomena in the Portimao Canyon area. Deep Sea Research Part II 53 (11-13), 1219-1240.

Candela, J., Winant, C.D., Ruiz, A., 1990. Tides in the Strait of Gibraltar. Journal of Geophysical Research 95, 7317-7335.

Carter, G.S., Gregg, M.C., 2002. Intense, variable mixing near the head of Monterey Submarine Canyon. Journal of Physical Oceanography 32, 3145-3165.

De Buen, R., 1924. Avance al estudio oceanográfico de la bahía de Algeciras. Boletín de Pescas IX (89), 1-32.

De Silva, I.P.D., Brandt, A., Montenegro, L.J., Fernando, H.J.S., 1999. Gradient Richardson number measurements in a stratified shear layer. Dynamics of Atmospheres and Oceans 30, 47-63.

Hibiya, T., 1986. Generation mechanism of internal waves by tidal flow over a sill. Journal of Geophysical Research 91, 7696-7708.
Kundu, P.K., Allen, J.S., Smith, R.L., 1975. Modal decomposition of the velocity field near the Oregon coast. Journal of Physical Oceanography 5, 638-704.

Kundu, P.K., 1990. Fluid Mechanics. Academic Press, New York, p. 658.

Kunze, E., Firing, E., Hummon, J.M., Chereskin, T.K., Thurnerr, A.M., 2006. Globa abyssal mixing inferred from lowered ADCP shear and CTD strain profiles. Journal of Physical Oceanography 36, 1553-1576.

Lee, C.Y., Beardsley, R.C., 1974. The generation of long nonlinear internal waves in a weakly stratified shear flow. Journal of Geophysical Research 79, 453-462.

Peltier, W.R., Caulfield, C.P., 2003. Mixing efficiency in stratified shear flows. Annual Review of Fluid Mechanics 35, 135-167.

Richez, C., 1994. Airborne synthetic aperture radar tracking of internal waves in the Strait of Gibraltar. Progress in Oceanography 33, 93-159.

Sánchez-Garrido, J.C., García Lafuente, J., Criado Aldeanueva, F., Baquerizo, A., Sannino, G., 2008. Time-spatial variability observed in velocity of propagation of the internal bore in the Strait of Gibraltar. Journal of Geophysical Research 113, C07034. http://dx.doi.org/10.1029/2007JC004624.

Vázquez, A., Stashchuk, N., Vlasenko, V., Bruno, M., Izquierdo, A., Gallacher, P.C. 2006. Evidence of multimodal structure of the baroclinic tide in the Strait of Gibraltar. Geophysical Research Letters 33, L17605.

Vázquez, A., Bruno, M., Izquierdo, A., Macías, D., Ruiz-Cañavate, A., 2008. Meteorologically-forced subinertial flows and internal wave generation at the main Sill of the Strait of Gibraltar. Deep-Sea Research I 55, 1277-1283.

Vázquez, A., Flecha, S., Bruno, M., Macías, D., Navarro, G., 2009. Internal waves and short-scale distribution patterns of chlorophyll in the Strait of Gibraltar and Alborán Sea. Geophysical Research Letters 36, L23601. http://dx.doi.org/ 10.1029/2009GL040959.

Viúdez, A., Pinot, J.M., Haney, R.L., 1998. On the upper layer circulation in the Alboran Sea. Journal of Geophysical Research 103 (C10), 21653-21666. http:// dx.doi.org/10.1029/98JC01082.

Vlasenko, V., Stashchuk, N., Hutter, K., 2005. Baroclinic Tides. Cambridge University Press, New York, p. 351.

Watson, G., 1994. Internal waves in a stratified shear flow: the Strait of Gibraltar Journal of Physical Oceanography 24, 509-517.

Watson, G., Robinson, L.S., 1990. A study of internal wave propagation in the Strait of Gibraltar using shore-based marine radar images. Journal of Physical Oceanography 20, 374-395.

Watson, G., Robinson, L.S., 1991. A numerical model of internal wave refraction in the Strait of Gibraltar. Journal of Physical Oceanography 21, 185-204.

Winters, K.B., Lombard, P.N., Riley, J.J., D’Asaro, E.A., 1995. Available potential energy and mixing in density-stratified fluids. Journal of Fluid Mechanics 289, 115-128. 